Research Article

\title{
Shaking Table Tests for Seismic Response of Oblique Overlapped Tunnel
}

\author{
Hao Lei $\mathbb{D}^{1,2}$ Honggang Wu $\mathbb{D}^{2},{ }^{2}$ and Tianwen Lai ${ }^{1}$ \\ ${ }^{1}$ School of Civil Engineering, Lanzhou Jiaotong University, Gansu 730000, China \\ ${ }^{2}$ Northwest Research Institute Co., Ltd., of C.R.E.C., Lanzhou, Gansu 730000, China \\ Correspondence should be addressed to Honggang Wu; 271462550@qq.com
}

Received 29 September 2020; Revised 21 December 2020; Accepted 12 January 2021; Published 25 January 2021

Academic Editor: Zengshun Chen

Copyright (C) 2021 Hao Lei et al. This is an open access article distributed under the Creative Commons Attribution License, which permits unrestricted use, distribution, and reproduction in any medium, provided the original work is properly cited.

To study the dynamic response and spectrum characteristics of the three-dimensional crossing tunnel under the action of seismic load, we established a 1/50 downscale model based on a typical of the oblique overlapped tunnel and conducted a series of shaking table tests. Through examining the recorded dynamic responses (acceleration and dynamic strain measured at different locations in model tunnels), we found that the seismic response of the crown was the largest at the central section, and the invert of the tunnels was exactly opposite to the crown, which presented a "parabolic" distribution, and we inferred that the damage within the model may be mainly concentrated on the crown of the tunnels. Additionally, the dynamic strain showed obvious nonlinear and nonstationary characteristics under the action of different degrees of seismic intensities. Different from a single tunnel, the acceleration superposition effect appears in the cross section of two tunnels because of the spatial effect of overlapping tunnels, resulting in the obvious seismic response in the cross section. Meanwhile, we also found that the 1st dominant frequency $(0.1-6.26 \mathrm{~Hz})$ seismic wave played a leading role in the process of tunnel slope failure. Furthermore, the analysis of the acceleration response spectrum also showed that the surrounding rock mass has an amplification effect on low-frequency seismic waves. These results help us better understand the features of the dynamic responses and also provide evidence to reinforce the overlapped tunnels against earthquakes.

\section{Introduction}

In general, owing to the constraints of the surrounding rock, it is considered that the dynamic response of tunnel and underground engineering under earthquake is quite different from that of other structures. However, with the occurrence of many large earthquakes, a large number of tunnel structures have been damaged to varying degrees, and many scholars also have different opinions on the dynamic response of tunnel engineering under seismic loads [1-3]. Nowadays, lots of overlapped tunnels are inevitable in practical engineering, such as highway tunnel-railway tunnel, highway tunnelhighway tunnel, railway tunnel-railway tunnel, and subway [4-6]. Owing to the complexity of the overlapped tunnel, its damage and earthquake resistance under the action of seismic loading have become the key issues.
In recent years, scholars mainly focused on field investigation, theoretical analysis, numerical simulation, and model test for the seismic response of underground structures in the past. Among these means, theoretical analysis and numerical simulation are the most widely used. For instance, Gazetas et al., Parra-Montesinos et al., Anastasopoulos et al., and Andreotti et al. [7-10] carried out theoretical analysis in the mechanical behavior of underground structures subjected to earthquake loading. They not only described the development of appropriate ground motion parameters, including peak accelerations and velocities, target response spectrum, and ground motion time history but also proposed that the seismic design loads of underground structures are characterized in terms of the deformations and strains imposed on the structure by the surrounding ground, often due to the interaction between 
the two $[11,12]$. These theories all provide references for the seismic dynamic response design of underground structures.

Different numerical approaches have been reported in the technical literature, for the investigation of tunnel dynamic response, for design, or for back-calculation of the dynamic test results in field or in the laboratory [13-15]. In the dynamic analysis approach, seismic dynamic response of the tunnel is conducted using numerical analysis tools such as finite element or finite difference methods. For instance, Khoshnoudian et al. and Ding et al. [16, 17] carried out the numerical simulation for large-scale seismic response analysis of the tunnel by taking account of nonlinear material behavior such as soil, nonreflecting boundary definition, and soil-tunnel interaction and provided relevant data and references for the aseismic design of underground structures. Additionally, it was reported by Sun and Dias $[18,19]$ that the stress redistribution caused by the tunneling process has an important effect on the seismic forces in the lining, and numerical results revealed that the target damping ratios and the damping determination approaches have an important influence on the tunnel dynamic response analyses.

Shaking table tests can directly reflect the deformations and failure mechanisms of tunnels under vibrations and are therefore an important means for studying the seismic dynamic response and instability failure mechanisms of tunnels $[20,21]$. The seismic performance of the rectangular tunnel under different excitations was studied, and the isolation mechanism of the damping layer was also discussed based on the centrifuge tests by Cilingir et al. and Chen et al. $[22,23]$. In addition, it has been found that the sudden change of stiffness or cross section would cause stress concentration in the shaking table test of the immersed tunnel under nonuniform excitation [24-26]. The shaking table tests were also conducted by Moss and Crosariol and Chen et al. et al. [27-29] for the overlapped subway tunnel, which found that the peak strain and damage degree on both sides of the tunnel model structure were distributed in the form of "S" along with the height. Furthermore, Kutter et al. Tsinidis et al., Zhao et al, and Wu et al. [30-33] not only conducted the shaking table tests of the subway but also used numerical simulation to verify the accuracy and rationality of the model. Zhang at al. [34] described discrepant responses between the cross passage and the twin tunnels by acceleration data. In the past study of the seismic performance of tunnel structures, researchers mainly focused on the dynamic response of single-line tunnels and subway tunnels. However, there are few shaking table tests on the overlapped tunnel, and no systematic research results have been obtained.

In this paper, the design of shaking table model tests for the overlapped tunnel is well first presented. Then, the peak acceleration and dynamic strain on the overlapped tunnels are discussed, and the specific section and measured point are analyzed in detail. Then, the wavelet packet is used to analyze the energy and spectrum of the invert of the upperspan tunnel and the crown of the under-crossing tunnel. Finally, a series of conclusions about the seismic response and seismic characteristics of the overlapped tunnel are drawn, which can provide a reference for the seismic design of such an overlapped tunnel.

\section{Shaking Table Tests}

2.1. Engineering Prototype. The Pandaoling tunnel is located in Zhenxing District, Dandong City, Liaoning Province, with a total length of $4870 \mathrm{~m}$ and a diameter of $7 \mathrm{~m}$, which is a single-track tunnel with a buried depth of about 17-106 m. The Strawberry ditch tunnel No. 1 is located in Strawberry ditch village, Dandong City, Liaoning Province, with a total length of $3205 \mathrm{~m}$ and a diameter of $10 \mathrm{~m}$, which is also a single hole double line tunnel with a maximum buried depth of about $105 \mathrm{~m}$. The Strawberry ditch tunnel No. 1 spans the Pandaoling tunnel at DK250+865-915. Further, the height difference of the rail surface at the intersection is $14.19 \mathrm{~m}$, and the net structure distance is $4.24 \mathrm{~m}$. The terrain position of the overlapping tunnel and the site position of tunnels are shown in Figure 1.

The rock formations in the cross section of the tunnel are mainly Proterozoic Sinian mixed granite, with relatively simple lithology, and the rock masses are gray-white. In addition, we used the TRT6000 advanced geological detector to forecast the geological conditions in the cross-affected zone, as shown in Figure 2. Within the mapping range, the blue range indicates that the geological structure of the section is weak, while the yellow range indicates that the geological structure of the section is hard. We found that surrounding rock was mainly composed of mixed granite with different weathering degrees with developed joint fissures, where it had $V_{S}$ (shear wave velocity) of $1000 \mathrm{~m} / \mathrm{sec}$ and $V_{p}$ (pressure wave velocity) of $2600 \mathrm{~m} / \mathrm{sec}$. Although the rock mass was relatively broken and there were surrounding rock cavities in some areas, no large-scale unfavorable geological structure had been discovered.

According to the relevant Chinese codes, the surrounding rock condition was set to the classification of grade IV, and the site area was in the area of the basic seismic intensity of grade VII. Owing to the poor nature of the surrounding rock in the area where the tunnel is located and the particularity of the overlapped tunnel, the tunnel may be severely damaged when an earthquake occurs and the traffic line may be paralyzed. Therefore, it is necessary to carry out the corresponding seismic response model test for the tunnel group in this area.

Here, blue points represent the receiving point, red points represent the source point, and each small grid represents $10 \mathrm{~m}$.

2.2. Similitude Relations. In this shaking table tests, the tunnel buried depth, section size, and shaking table size are considered comprehensively. Additionally, the design of the test model is reasonable and meets the geometric similarity to the greatest extent [35]. The similarity ratios of key controlling factors based on the Buckingham- $\pi$ theorem are summarized in Table 1. The similarity ratio of length $C_{L}$, Young's modulus $C_{E}$, and density $C_{\rho}$ are predetermined as $1 /$ $50,1 / 30$, and $1 / 1$, respectively. 


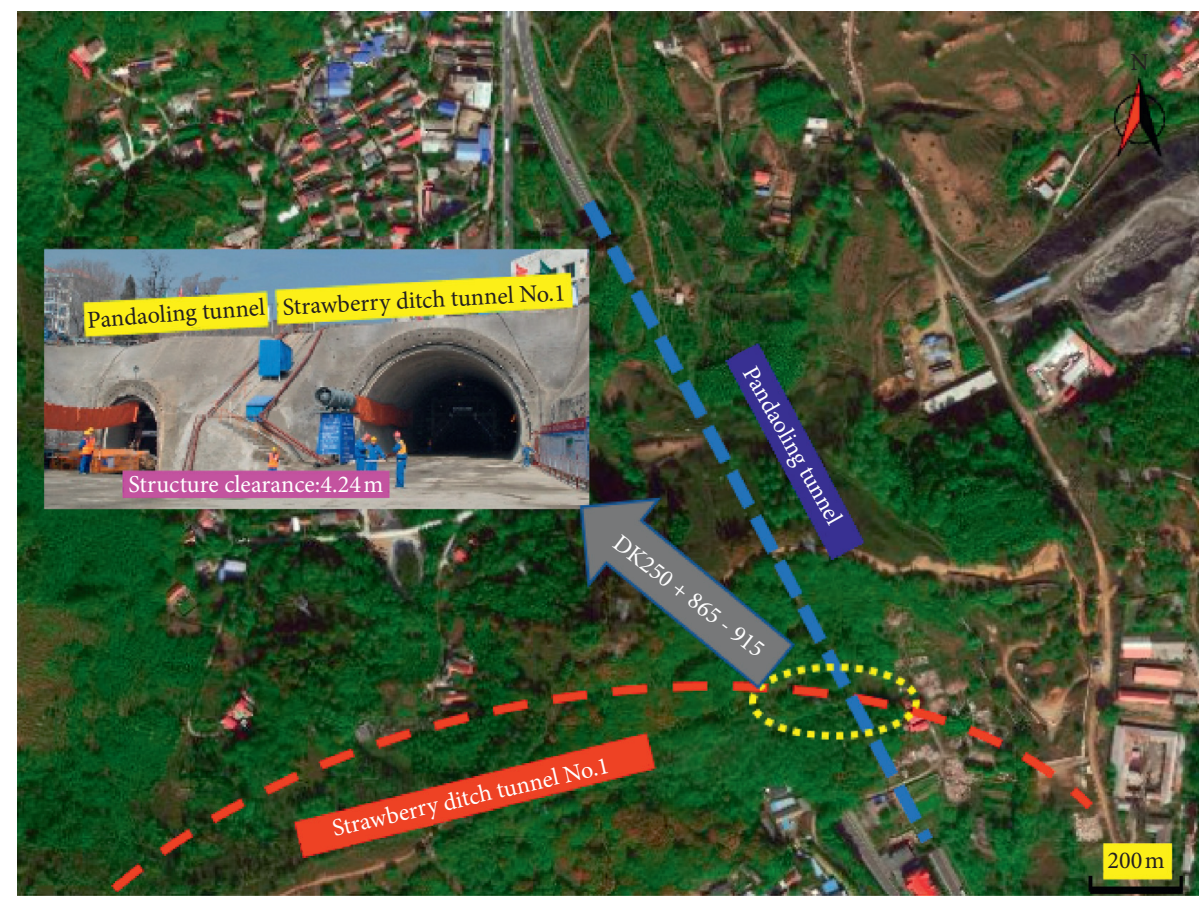

FIGURE 1: Engineering prototype of the overlapped tunnel.

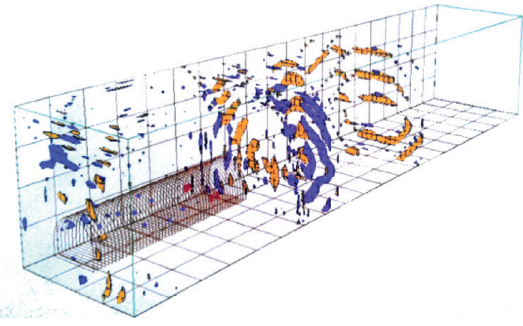

(a)

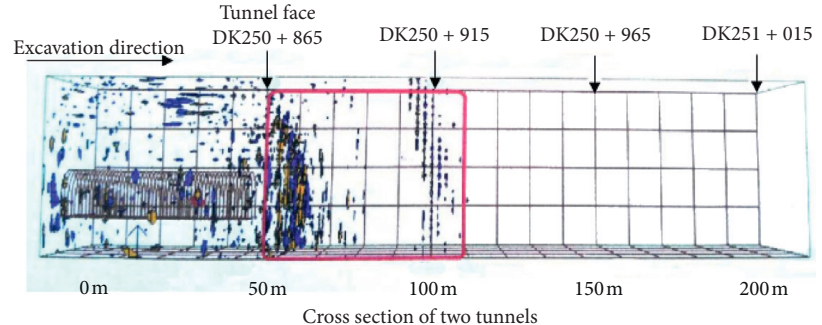

(b)

FIgURE 2: TRT detection reflection imaging hologram: (a) three-dimensional stereogram and (b) right-side view.

TABLE 1: Similarity relations and ratios.

\begin{tabular}{lcc}
\hline Physical parameters & Symbol and relational expression & Similarity ratio \\
\hline Length $(L)$ & $C_{L}$ & $1 / 50$ \\
Density $(\rho)$ & $C_{\rho}$ & $1 / 1$ \\
Elastic modulus $(E)$ & $C_{E}$ & $1 / 30$ \\
Stress $(\sigma)$ & $C_{\sigma}=C_{E} C_{\varepsilon}$ & $1 / 30$ \\
Strain $(\varepsilon)$ & $C_{\varepsilon}=1$ & 1 \\
Poisson's ratio $(\mu)$ & $C_{\mu}=1$ & 1 \\
Internal friction angle $(\phi)$ & $C_{\phi}=1$ & 1 \\
Time $(t)$ & $C_{t}=C_{\rho}^{0.5} C_{E}^{-0.5} C_{L}$ & $1 / 9.129$ \\
Displacement $(d)$ & $C_{d}=C_{L}$ & $1 / 50$ \\
Velocity $(v)$ & $C_{v}=C_{\rho}^{0.5} C_{E}^{0.5}$ & $1 / 0.183$ \\
Acceleration $(a)$ & $C_{a}=C_{\rho}^{-1} C_{E} C_{L}^{-1}$ & $1 / 0.6$ \\
\hline
\end{tabular}

For example, according to the similarity relationship, it can be deduced that the diameter of the tunnel section is $20 \mathrm{~cm}$ and the thickness of primary lining is $0.5 \mathrm{~cm}$ and secondary lining is $1 \mathrm{~cm}$. As a summary, the properties of surrounding rock similar material and lining similar materials are tabulated in Table 2. Their counterparts in the engineering prototype, which were collected from the design document of the tunnel, are also listed in Table 2 for comparison. 
TABle 2: Physical and mechanical parameters of similar materials.

\begin{tabular}{|c|c|c|c|c|c|}
\hline Similar material & & $E(\mathrm{GPa})$ & $\rho\left(\mathrm{kg} / \mathrm{m}^{3}\right)$ & $c(\mathrm{kPa})$ & $\phi\left(^{\circ}\right)$ \\
\hline \multirow{2}{*}{ Surrounding rock } & Prototype & $1.3-6$ & $2000-2300$ & $200-700$ & $27-39$ \\
\hline & Model & 0.14 & 2270 & 10.47 & 34.80 \\
\hline \multirow{2}{*}{ Lining structure } & Prototype & 31.5 & 2300 & - & - \\
\hline & Model & 1.05 & 2180 & - & - \\
\hline
\end{tabular}

2.3. Similar Materials. Through the above similar relationship and considering the economics and feasibility of the actual material, the main materials used in this test are cement, coarse sand, water, and soil. Taking grade IV surrounding rock as an example, the orthogonal test design method, direct shear test, and triaxial test were used to determine similar material parameters. It is noted that the effectiveness of using these mixed materials to simulate the surrounding rock has been validated by the former study $[36,37]$. To improve efficiency, only a single parameter was changed at a time and a total of 5 sets of ratio experiments were designed. The specific ratio and its mechanical parameters are shown in Table 3.

According to the above tests and similar relations, the proportion of similar materials in surrounding rock was finally determined. The surrounding rock of the prototype was simulated by a similar material, which was blended by cement, coarse, sand, soil, and water, with their mass mixture ratios of $0.5 \%: 12 \%: 5 \%: 2 \%$. In the test, the thickness of the primary and second lining $(0.5 \mathrm{~cm}$ and $1 \mathrm{~cm})$ of the tunnel model was small, which was regarded as the whole structure (lining structure). Moreover, the lining structure similar material was made up of gypsum, quartz sand, and water by their mass mixing ratio of $10 \%, 15 \%$, and $20 \%$. The model of the tunnel and lining structure is shown in Figure 3.

2.4. Model Design. To simultaneously analyze the response of the overlapped tunnels with different crossing forms, the model was set up with left and right sides, and the left side was the orthogonal type and the right side was the oblique type, respectively. This study mainly focused on the right oblique overlapped tunnel, and the response of the overlapped tunnel on the left will be described in other articles.

The tests were performed in combination with the servodriven seismic simulation shake table system of the Lanzhou Institute of Seismology of the China Earthquake Administration. The laboratory adopts VPS-600ES-2 bidirectional ( $X$ direction, $Z$ direction, and $X Z$ direction) shaking table; the size of the vibration table is $4 \times 6 \mathrm{~m}$, the maximum load is $25 \mathrm{t}$, the working frequency is $0.1 \sim 50.0 \mathrm{~Hz}$, and the maximum displacement is $\pm 250 \mathrm{~mm}$ in the $X$ direction, $\pm 100 \mathrm{~mm}$ in the $Z$ direction, and $\pm 150 \mathrm{~mm}$ in the $X Z$ direction $[38,39]$.

The size of the model box is $2.80 \mathrm{~m}$ in length $\times 1.40 \mathrm{~m}$ in width $\times 1.80 \mathrm{~m}$ in height, which both sides are composed of U-shaped steel plates and plexiglass. Considering the influence of "rigid model box boundary effect," we dealt with the model box boundary. The boundary of the model box perpendicular to the horizontal excitation direction can generate shock reflection of the seismic wave, which makes the wave propagation quite different. The $5 \mathrm{~cm}$ thick polystyrene foam board was adhered to the inner wall of the model box, which was treated as a flexible boundary. Additionally, the seismic wave is input from the bottom of the model box, so there should be no relative sliding between the model soil and the bottom plate of the box. A layer of $5 \mathrm{~cm}$ thick gravel soil was laid on the bottom plate of the model box to increase the friction force. The particle size of the gravel was about $2 \mathrm{~cm}$, and the bottom plate was treated as a friction boundary. Furthermore, a smaller polystyrene foam ring was adhered to the tunnel portal, which was treated as a sliding boundary to prevent the tunnel structure from being affected by the vibration of the box. The model layout is shown in Figure 4.

2.5. Test Section and Sensor Arrangement. This paper mainly studied the dynamic response characteristics of the affected section, surrounding rock, and slope body of the overlapped tunnel on the right side of the model box. Therefore, a total of 16 accelerometers were mainly arranged in the crown and invert axis of the tunnel, the cross-influence section of the two tunnels, and the inside of the slope body. Apart from this, 8 dynamic strain gauges were pasted on the outside of the two tunnels, respectively. The accelerometers are threephase capacitive with a sensitivity of $680 \mathrm{mV} / \mathrm{g}$ in the horizontal direction, $680 \mathrm{mV} / \mathrm{g}$ in the $X$ direction, $680 \mathrm{mV} / \mathrm{g}$ in the $Z$ direction, and $\pm 2 \mathrm{~g}$ in range. The size of each accelerometer is $13 \mathrm{~mm} \times 15 \mathrm{~mm} \times 8 \mathrm{~mm}$. The dynamic strain gauges have a sensitive grid size of $9.8 \mathrm{~mm} \times 3.0 \mathrm{~mm}$ and a base size of $15.5 \mathrm{~mm} \times 5.0 \mathrm{~mm}$, with a sensitivity coefficient of $2.0-2.20$ and a temperature range of $-30-80^{\circ} \mathrm{C}$. The central cross section of the upper-span and under-crossing tunnels was set to I and $\mathrm{I}^{\prime}$, respectively, and the two sides of the affected section $30 \mathrm{~cm}$ away from the central cross section were marked as II, III, II', and III', respectively. The layout of the accelerometers and dynamic strain gauges is shown in Figure 5, where the accelerometers SA2, SA5, XA2, $\mathrm{XA5}$, and PA1-PA4 were set on the central cross section and the dynamic strain gauges ZS2, ZS5, ZS7, and ZS8 (ZX2, ZX5, ZX7, and ZX8) were set on the central cross section I $\left(I^{\prime}\right)$ as well. Additionally, accelerometers and dynamic strain gauges were only set on the crown and invert of the affected sections II and III (II' and III').

2.6. Input Ground Motions. During the loading process, sine waves, EL-Centro, and WenChuan (WC) waves were inputted in horizontal $(X)$ and horizontal-vertical $(X Z)$ direction, respectively, as shown in Figure 6(a). The seismic waves selected as input ground motions in the shaking table 
TABLE 3: Orthogonal design of similar material ratios.

\begin{tabular}{|c|c|c|c|c|}
\hline \multirow{2}{*}{ Mechanical parameters } & \multicolumn{4}{|c|}{ Material ratio } \\
\hline & $E(\mathrm{GPa})$ & $\rho\left(\mathrm{kg} * \mathrm{~m}^{-3}\right)$ & $C(\mathrm{kPa})$ & $\phi\left({ }^{\circ}\right)$ \\
\hline 1. Cement: coarse sand: soil: water $=1: 15: 5: 2$ & 0.32 & 2420 & 11.26 & 39.61 \\
\hline 2. Cement: coarse sand: soil: water $=2: 15: 5: 2$ & 0.23 & 2440 & 23.95 & 42.64 \\
\hline 3. Cement: coarse sand: soil: water $=1: 12: 5: 2$ & 0.10 & 2260 & 24.42 & 35.85 \\
\hline 4. Cement: coarse sand: soil: water $=0.5: 12: 5: 2$ & 0.14 & 2270 & 10.47 & 34.80 \\
\hline 5. Cement: coarse sand: soil: water $=0.5: 10: 5: 2$ & 0.19 & 2350 & 11.76 & 36.09 \\
\hline Prototype (grade IV surrounding rock) & $1.3-6$ & $2000-2300$ & $200-700$ & $27-39$ \\
\hline
\end{tabular}

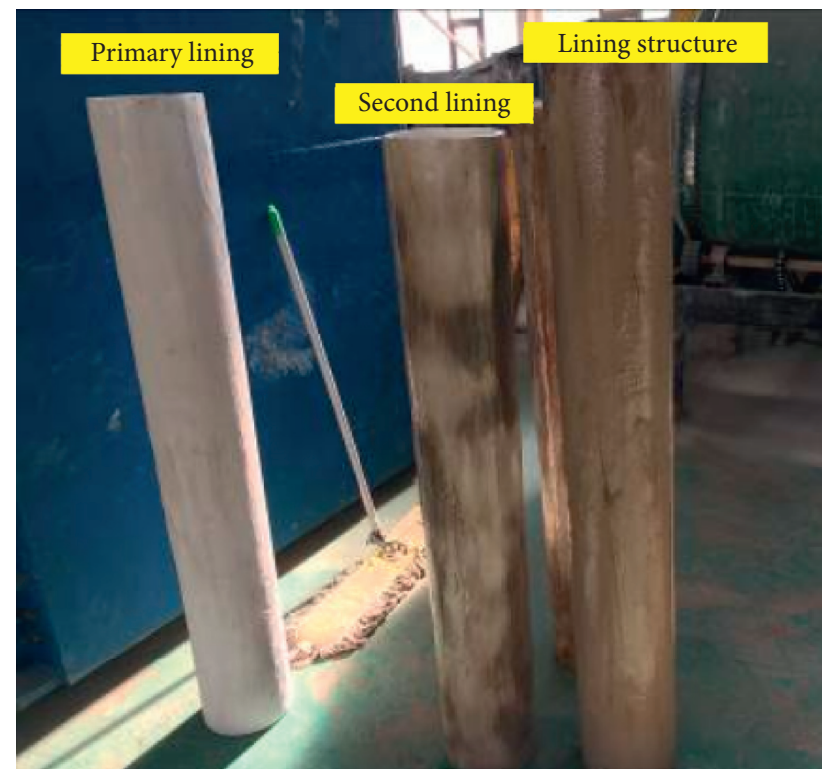

Figure 3: The tunnel and lining structure.

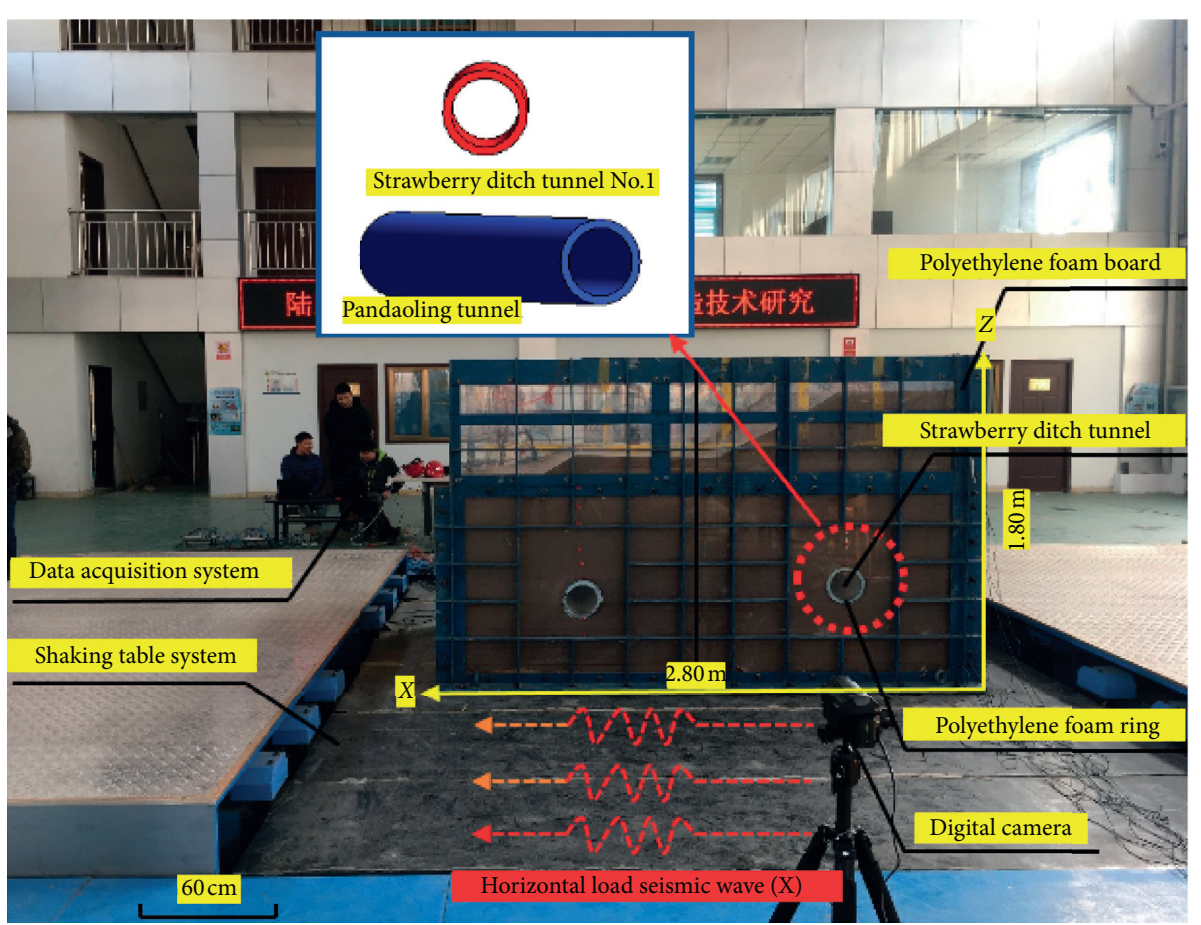

Figure 4: The layout of the test model. 


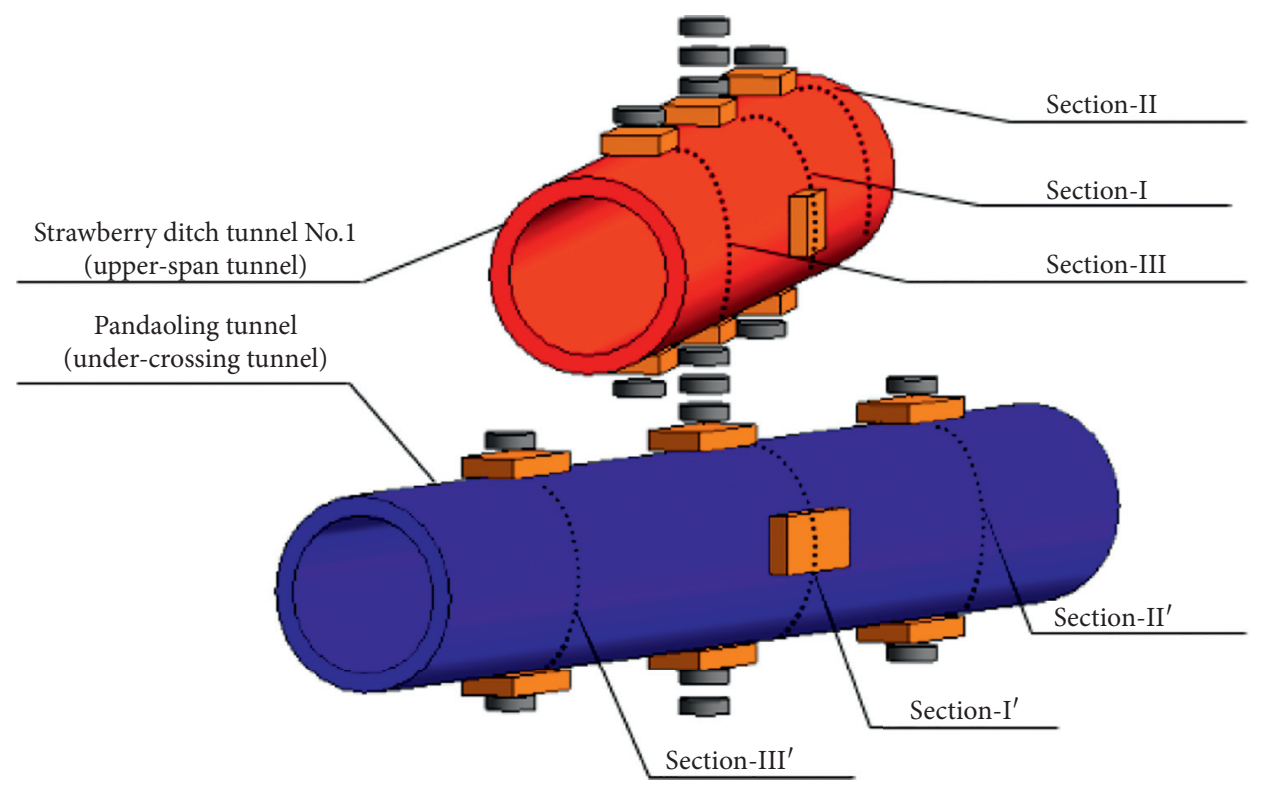

- Accelerometer

Dynamic strain gauge

(a)
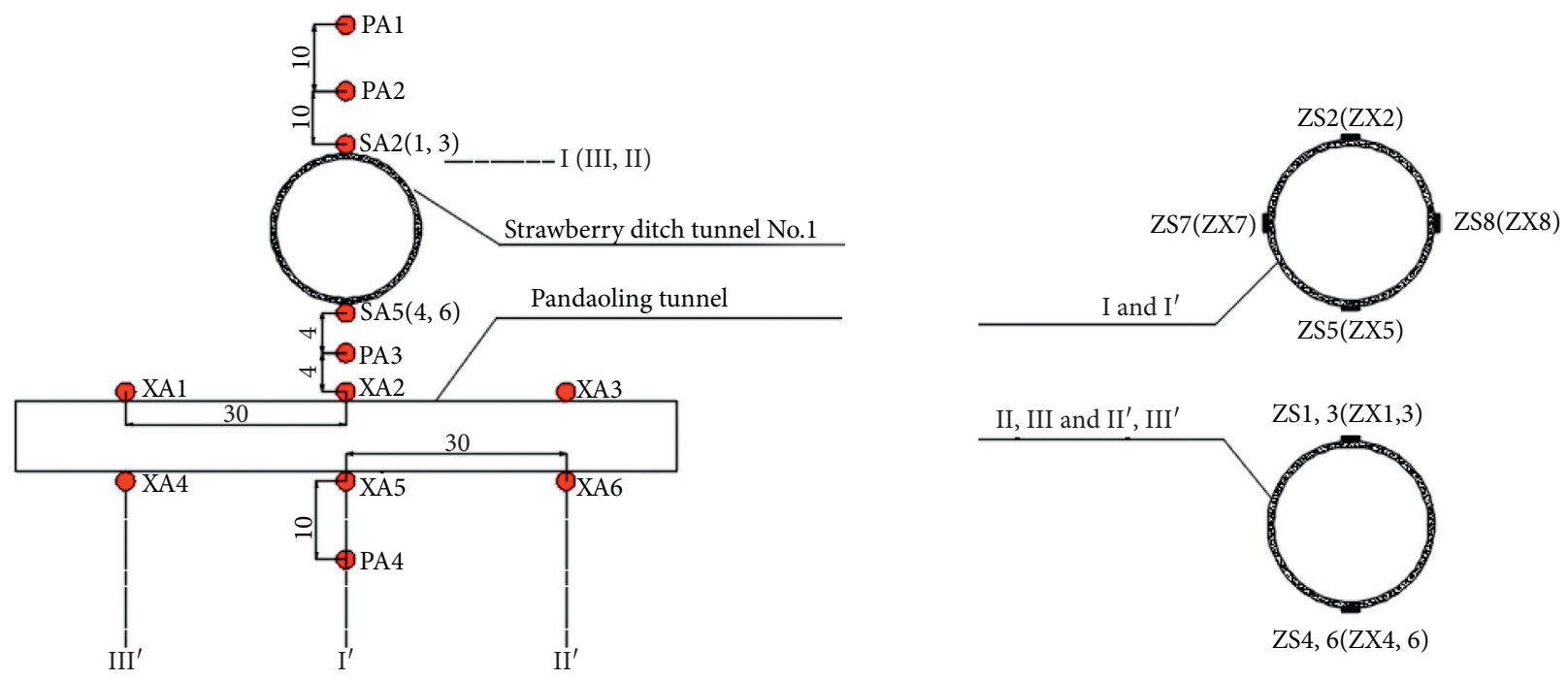

- Accelerometer

- Dynamic strain gauge

(b)

Figure 5: The arrangement of the sensor: (a) 3D schematic and (b) plan sketch (unit: $\mathrm{cm}$ ).

tests were sine wave and EL-Centro wave and were inputted in $X$ direction in this paper. The EL-Centro earthquake record (Imperial Valley earthquake (Mw 6.9) in Southeastern California, USA) is the first strong earthquake record obtained by humans with a maximum acceleration exceeding 300 gal. Additionally, another important reason for choosing to load seismic waves is that the response spectrum of the EL-Centro seismic wave is in good agreement with the design response spectrum of Chinese seismic code (Code for seismic design of buildings GB50011-2010). Some previous studies $[40,41]$ have shown that horizontal earthquakes were the main cause of tunnel structural damage and landslides. Therefore, this paper only analyzed the dynamic response of one-way horizontal input seismic waves.

Moreover, if the time compression ratio of the seismic wave is less than $1: 3.16$ in the shaking table test, it will cause the seismic wave spectral components to be too complex and produce distortion, which will lead to adverse effects on the acquisition and processing of test data [42]. In this test of the manuscript, the time similarity ratio is $1: 9.129$, less than 1 : 1.316. Considering these factors, the seismic waves in the test were not compressed in time similarity ratio, and the 


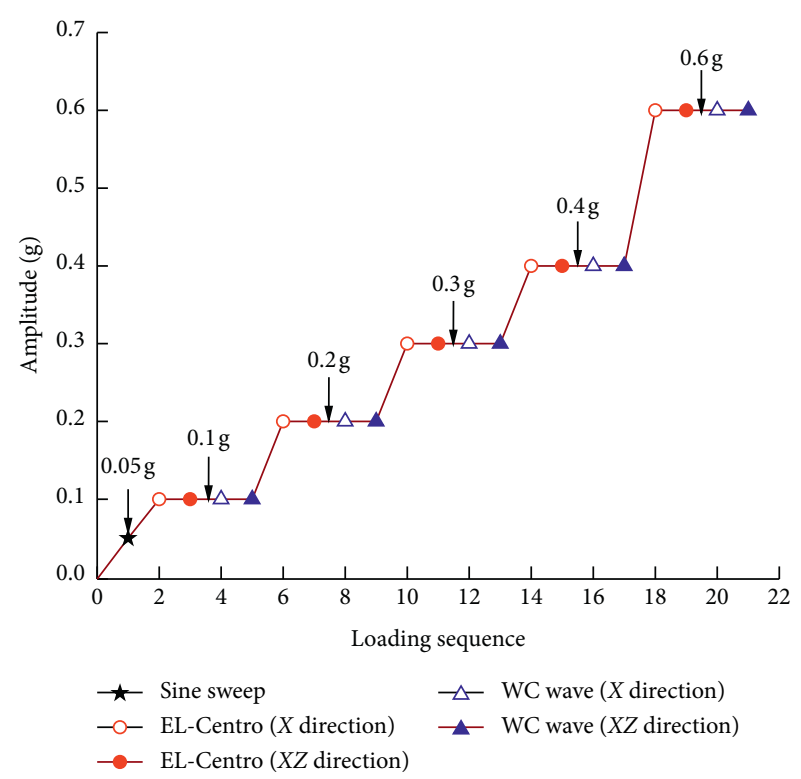

(a)

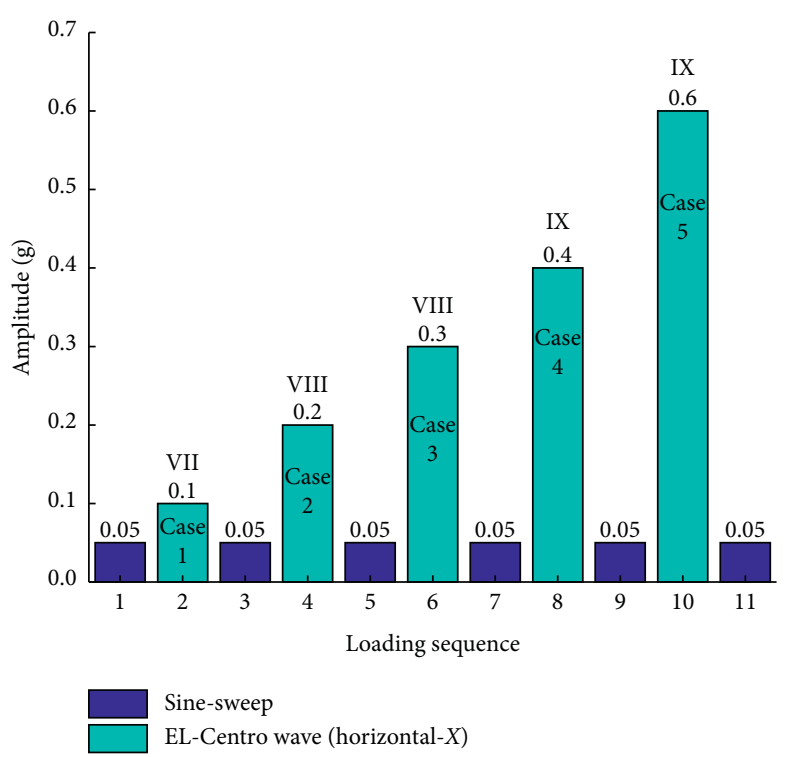

(b)

FIGURE 6: Loading sequence of the shaking table test: (a) all loading process and (b) cases analyzed in this paper.

original wave of the EL-Centro wave was input during the shaking table test. When the input peak value of acceleration is $0.1 \mathrm{~g}$, the acceleration time-history curve of the EL-Centro wave at the measuring point tabletop of the shaking table is shown in Figure $7(\mathrm{a})$. The sampling interval is $\triangle T=0.0013 \mathrm{~s}$, the peak acceleration is $0.982 \mathrm{~m} / \mathrm{s}^{2}$, and the main vibration duration is about $23 \mathrm{~s}-65 \mathrm{~s}$, a total of $42 \mathrm{~s}$. The Fourier spectrum of the EL-Centro wave is shown in Figure 7(b), the predominant frequency is $1.0-2.5 \mathrm{~Hz}$, the maximum amplitude is about 0.019 , and the amplitude of the seismic wave above $20 \mathrm{~Hz}$ is almost zero.

The peak acceleration of ground motion along the engineering prototype site area is $0.15 \mathrm{~g}$, and the characteristic period of the ground motion response spectrum is $0.35 \mathrm{~s}$, which belongs to the basic earthquake intensity zone of grade VII. To meet the seismic design requirements of frequent, fortified, and rare earthquakes of the prototype area, the peak values of input waves were $0.1,0.2,0.3$, and $0.4 \mathrm{~g}$, respectively. Additionally, to explore the failure mode of the tunnel model under extreme earthquakes, $0.6 \mathrm{~g}$ was designed and loaded, as presented in Figure 6(b). Therefore, by inputting the designed seismic wave, all kinds of failure modes and dynamic response of the overlapped tunnel model are analyzed comprehensively under different seismic loads. Furthermore, to test the dynamic characteristics of the system and study the damage of the system with the input seismic, the sine-sweep (with the PGA of $0.05 \mathrm{~g}$ ) was inputted when the amplitude of input seismic was changed.

\section{Seismic Responses of the Model}

\subsection{Dynamic Response Analysis of the Upper-Span Tunnel}

3.1.1. Acceleration. To compare the different dynamic response of the acceleration of the tunnel crown and invert under the same cases, the upper and lower horizontal axes were set as different section positions, while the left and right longitudinal axes were set as peak acceleration (Figure 8).

It can be seen from Figure 8 that the distribution and change of the peak acceleration of the upper-span tunnel show a certain regularity; that is, with the increase in the PGA, the peak acceleration at each measured point increases accordingly. For the crown of the upper-span tunnel, the peak acceleration is the largest at the section-I in the center of the intersection, and the peak acceleration values at the section-II and section-III on both sides of the affected section are almost equal, which is approximate "parabola" distribution. On the other hand, for the invert of the upperspan tunnel, the peak acceleration at the measured point SA5 significantly decreases, and their magnitudes are as follows: section-II < section-I < section-III, which is in an "oblique line" distribution. At the same time, it can also be seen that the peak acceleration at the invert of the section-I is significantly smaller than that at the crown, which is more variable than the other two sections. Taking the PGA of $0.4 \mathrm{~g}$ as an example, the peak acceleration of the crown of the section-I is 1.43 times of that of the invert, while the peak acceleration of the crown of the section-II and section-III are 0.91 times and 0.95 times of that of the invert, respectively. Due to the shallow buried depth of the upper-span tunnel, the crown has less absorption of the seismic wave, which makes its acceleration response more intense. However, the soil mass at the invert is squeezed more closely because of the existence of the underpass tunnel, and the seismic wave absorption is obvious.

As the cross section is the key study object, the time history of acceleration at the invert (SA5) of section-I in the center of the intersection under different cases was also analyzed, as shown in Figure 9. When the PGA of 0.1, 0.2, $0.3,0.4$, and $0.6 \mathrm{~g}$ seismic waves were inputted, the peak 


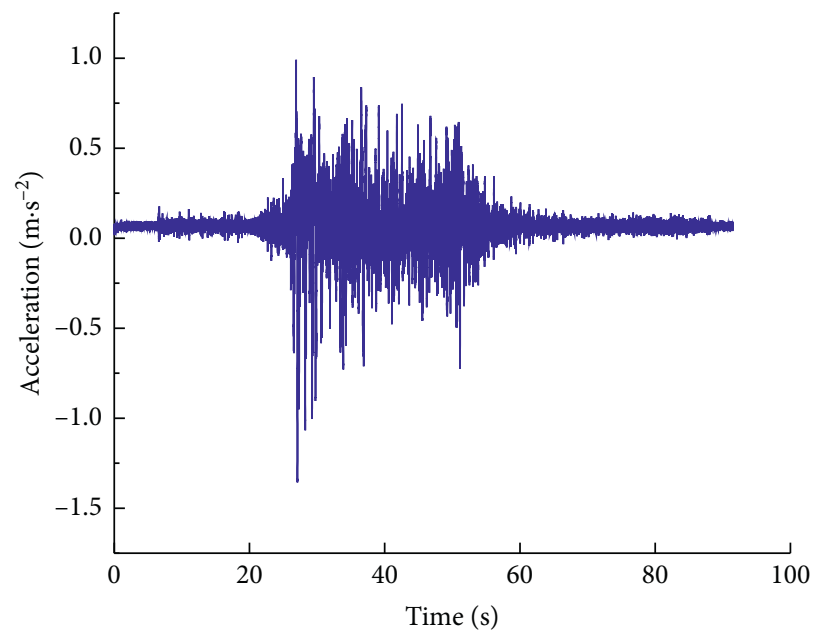

(a)

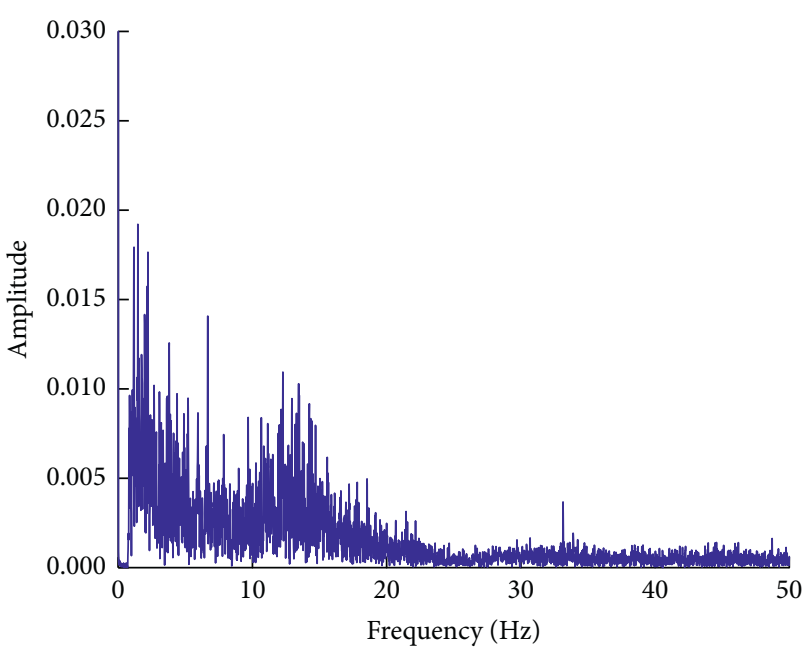

(b)

FIgURE 7: Time-frequency characteristic curve of the EL-Centro wave: (a) time history; (b) Fourier spectrum.

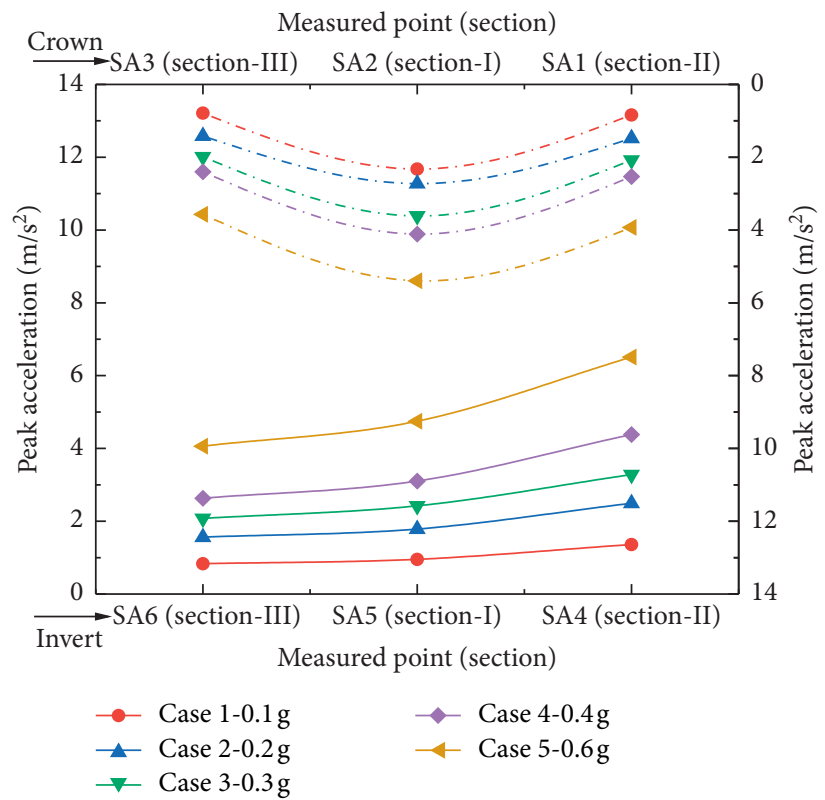

Figure 8: Peak acceleration of the upper-span tunnel.

accelerations were $0.95,1.78,2.39,3.06$, and $4.57 \mathrm{~m} / \mathrm{s}^{2}$, respectively, and the peak acceleration basically occurred within 20-40 s after loading. Furthermore, the growth rate of peak acceleration is slow in the range of $0.1-0.3 \mathrm{~g}$, while it changes greatly in the range of $0.4-0.6 \mathrm{~g}$, which indicates that the invert of the upper-span tunnel is more sensitive to the high intensity seismic wave.

To more clearly illustrate the changing trend of crown and invert of the upper-span tunnel under different cases, we define the peak acceleration ratio $\left(R_{a}\right)$, as shown in equation (1), which is the ratio of the peak acceleration of each measured point under other cases (Case2-5) to the peak acceleration with the PGA of $0.1 \mathrm{~g}$. It can be seen from the above that with the PGA of $0.1 \mathrm{~g}$, the peak acceleration of the crown (invert) of section-I, II, and III is $2.33,0.84$, and $0.79 \mathrm{~m} / \mathrm{s}^{2}\left(0.95,1.36\right.$, and $\left.0.83 \mathrm{~m} / \mathrm{s}^{2}\right)$, respectively. The results are shown in Figure 10. The peak acceleration of each section at the crown is more sensitive to the change of input cases, while the change of each section at the invert is more stable. Moreover, the acceleration magnification effect is smaller before $0.2-0.4 \mathrm{~g}$, and $R_{a}$ is 2.55 at the maximum, while $R_{a}$ has a sharp increase after $0.4 \mathrm{~g}$, which reaches 5.01 at the maximum. In particular, the dynamic response of acceleration at the SA2 of the crown does not change significantly 

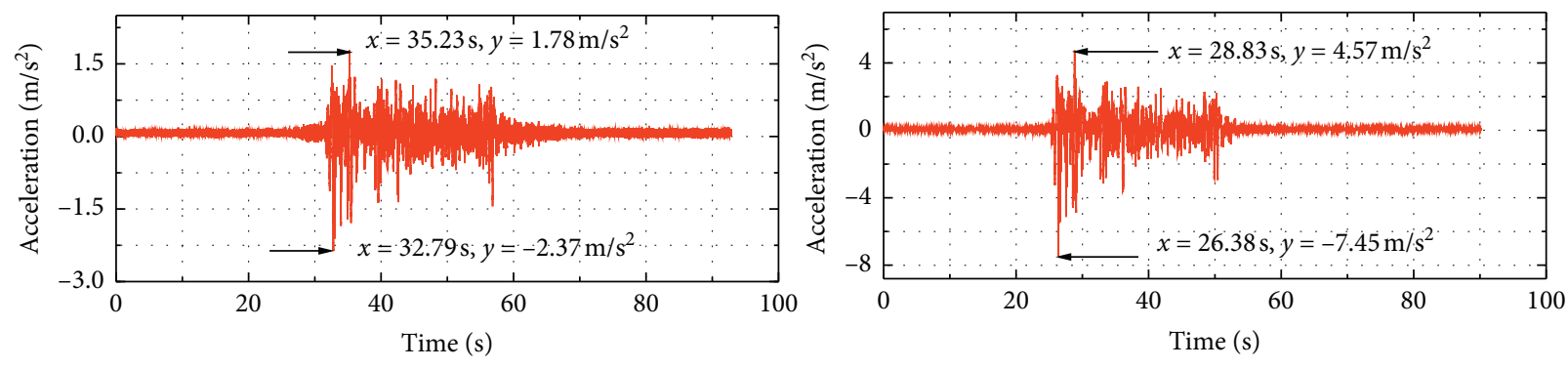

$-0.2 \mathrm{~g} \mathrm{EL}$

$-0.6 \mathrm{~g} \mathrm{EL}$
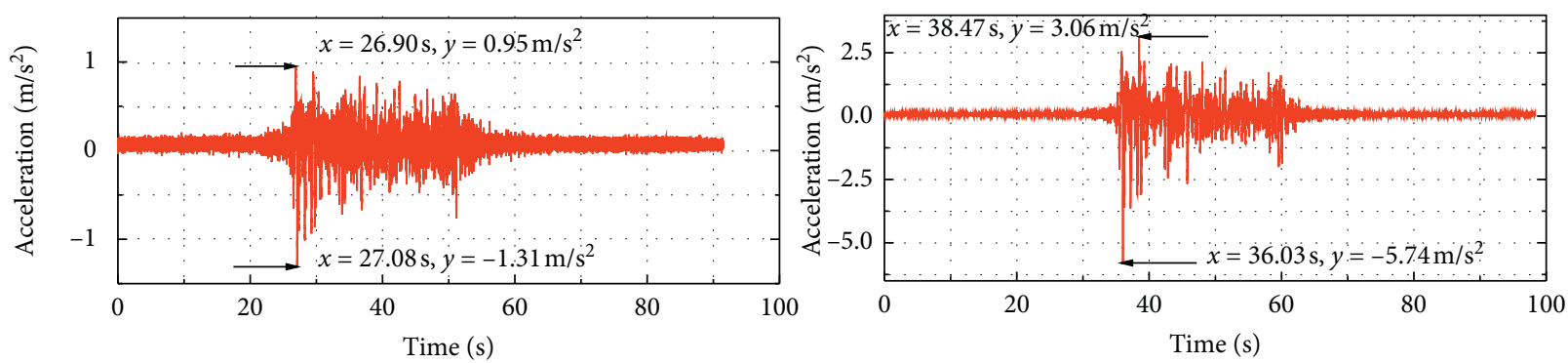

- $0.1 \mathrm{~g} \mathrm{EL}$

$-0.4 \mathrm{~g} \mathrm{EL}$
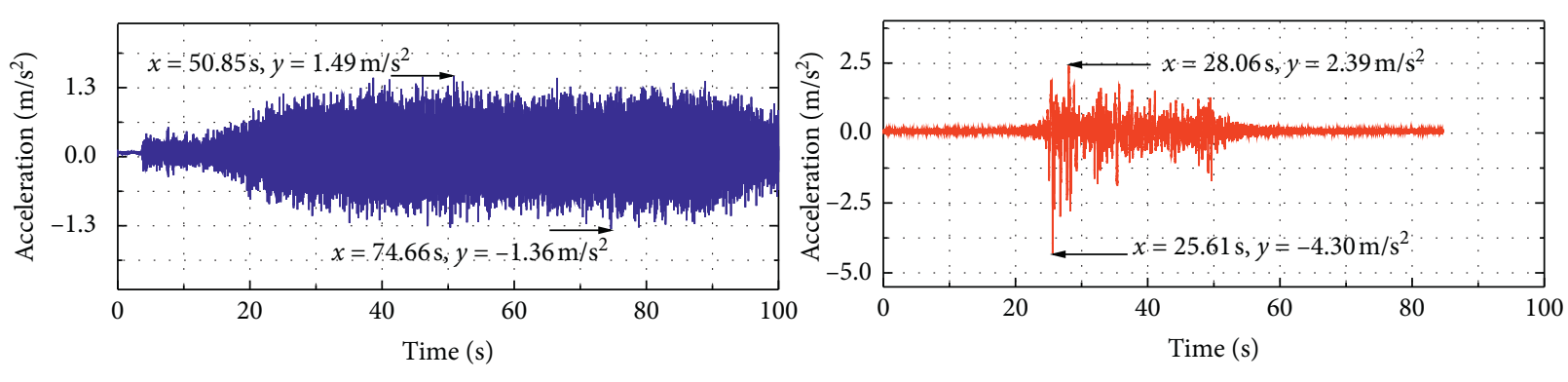

— $0.05 \mathrm{~g}$ sine-sweep

$-0.3 \mathrm{~g} \mathrm{EL}$

FIGURE 9: Time-history curve of acceleration at the invert (SA5) of the upper-span tunnel.

with the different input seismic amplitude, while the seismic response of acceleration at the invert (SA5) has a noticeable transformation.

$$
R_{a}=\frac{R_{a i j}}{R_{a 1 j}}
$$

where $i$ denotes different cases, $i=2,3,4$, and 5 and $j$ denotes different measured points, $j=1,2,3,4,5$, and 6 . For example, $R_{a 11}$ is the peak acceleration of measured point SA1 in Case 1 (with the PGA of $0.1 \mathrm{~g}$ ).

3.1.2. Dynamic Strain. This section mainly compared and analyzed the circumferential strain of the central section (section-I) of the intersection under different cases, as shown in Figure 11.

The results illustrate that the peak values of strain under different cases show basically the same law when different amplitude seismic waves are inputted. With the increase in the input seismic amplitude, the peak strain of each measured point increases, and the "envelope" of the peak strain gradually spreads out. As for the Cases 1 and 2, the peak strain at each measured point is crown $(\mathrm{ZS} 2)>$ side walls

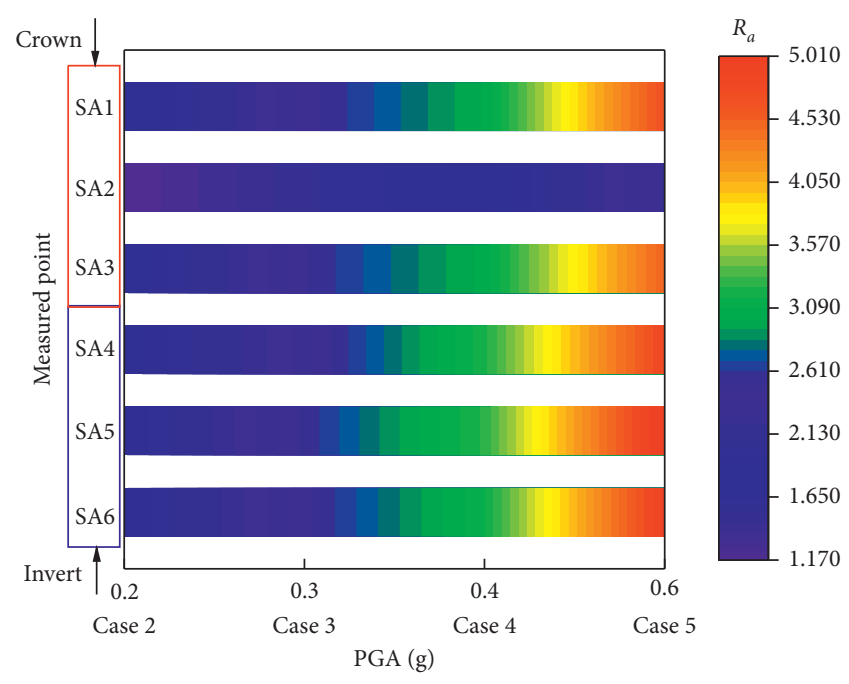

Figure 10: $R_{a}$ of the upper-span tunnel.

(ZS8 and ZS7) $>$ invert (ZS5). However, the peak strain at each measured point is side walls $>$ crown $>$ invert when the inputted seismic wave amplitude is large (Case 3-5). The 


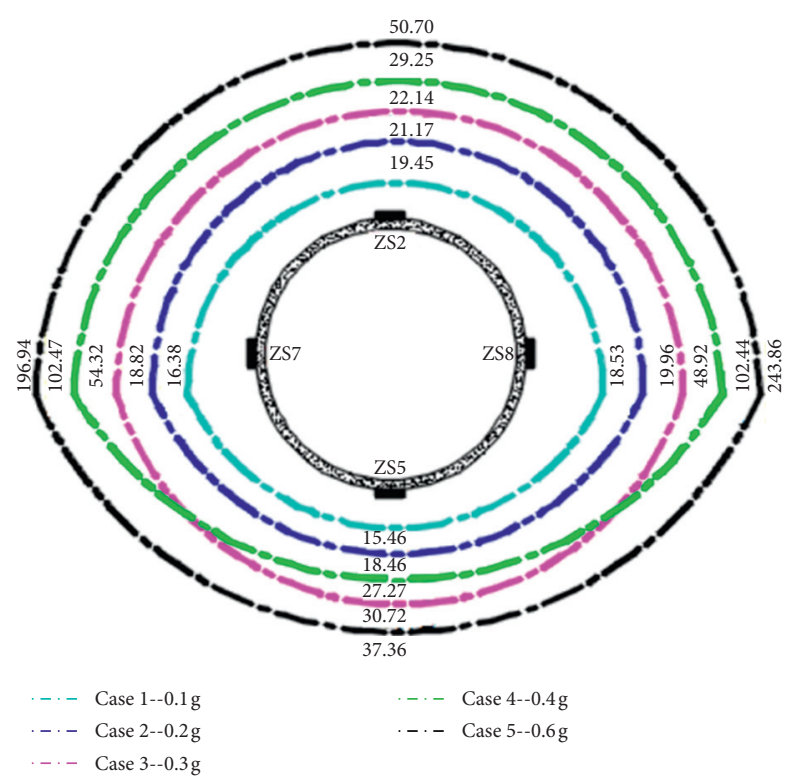

FIGURE 11: An envelope of circumferential peak strain of the upperspan tunnel (unit: $\mu \varepsilon$ ).

reason for this is that the displacement of the invert at the cross section of the upper-span tunnel is limited by the surrounding rock mass owing to the influence of the undercrossing tunnel. Further, on both sides of the side walls, the strain is relatively increased because of the small limit of the surrounding rock.

We also define the peak strain ratio $\left(R_{s}\right)$, as shown in equation (2), which is the ratio of the peak strain of each measured point under other cases (Case 2-5) to the peak strain with the PGA of $0.1 \mathrm{~g}$. Based on the peak value of each measured point in Case 1 (the PGA of $0.1 \mathrm{~g}$ ), Figure 12 presents the amplification factor of each case. It is implied that the maximum $R_{s}$ generated by the side wall is 13.16 , which indicates that the side wall of the upper-span tunnel is the most sensitive to the seismic load response, followed by the crown, and the invert is the least obvious. Since the inputting direction is the direction of the cross section, the side wall of the tunnel is first subjected to seismic loading, and the effect is the strongest at this time. In addition, owing to the shallow depth of the crown of the tunnel, the absorption of the seismic waves by the surrounding rock is not obvious, and the soil body squeezes the tunnel to produce a large displacement, resulting in a large strain response. It is noted that this kind of view has also been presented in some former studies $[43,44]$.

$$
R_{s}=\frac{R_{s i j}}{R_{s 1 j}},
$$

where $i$ denotes different cases, $i=2,3,4,5$ and $j$ denotes different measured points, $j=2,5,7,8$. For example, $R_{s 12}$ is the peak strain of measured point ZS2 in Case 1 (with the PGA of $0.1 \mathrm{~g}$ ).

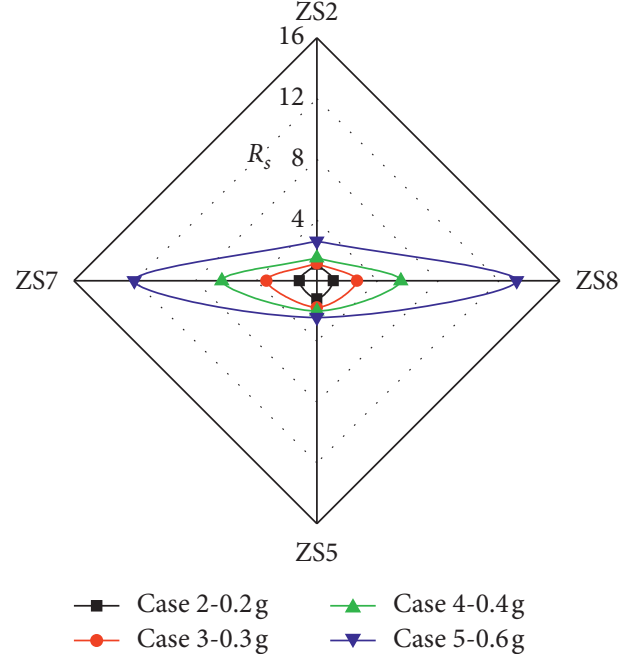

FIgURE 12: $R_{s}$ of the upper-span tunnel.

\subsection{Dynamic Response Analysis of the Under-Crossing Tunnel}

3.2.1. Acceleration. The peak value of the acceleration of the crown and the invert of the under-crossing tunnel is also analyzed in Figure 13. For the crown of the under-crossing tunnel, the peak acceleration at the intersection section-I' (XA2) is the largest, followed by the section-III' (XA3) in the affected section, and the acceleration peak at the section-II' (XA1) is the smallest, respectively. It is clear that the distribution of acceleration response at different sections is approximate "parabola" under the same case. However, the peak acceleration at the XA5 in section I' is the smallest and at the XA4 and XA6 on both sides of the affected section are basically equal, which shows an approximate linear distribution. Additionally, it can also be seen that under different cases, the peak acceleration of the crown of the undercrossing tunnel is less than the invert, and the fluctuation of the peak acceleration of each cross section crown is not obvious. This is the reason why the crown is inclined to become a potential seismic damage area, which is very easy to cause damage to the model of the upper-span tunnel.

The time history of acceleration at the crown (XA2) of section- $\mathrm{I}^{\prime}$ in the center of the intersection under different cases is analyzed, as shown in Figure 14. It can also be seen from the time history that with the increase in the amplitude of the inputted EL-Centro wave, the acceleration response at the crown of the under-crossing tunnel changes smoothly. The peak acceleration is $4.04,3.94,4.02,4.12$, and $4.20 \mathrm{~m} / \mathrm{s}^{2}$ when the PGA is $0.1,0.2,0.3,0.4$, and $0.6 \mathrm{~g}$ seismic waves, respectively, and the peak acceleration basically occurs within 20-40 s after loading. Different from the invert of the upper-span tunnel, the seismic response at the crown of the under-crossing tunnel is larger all the time, and its proportion is about 1 , which indicates that the seismic response of the crown does not change significantly with the amplitude of seismic waves. 


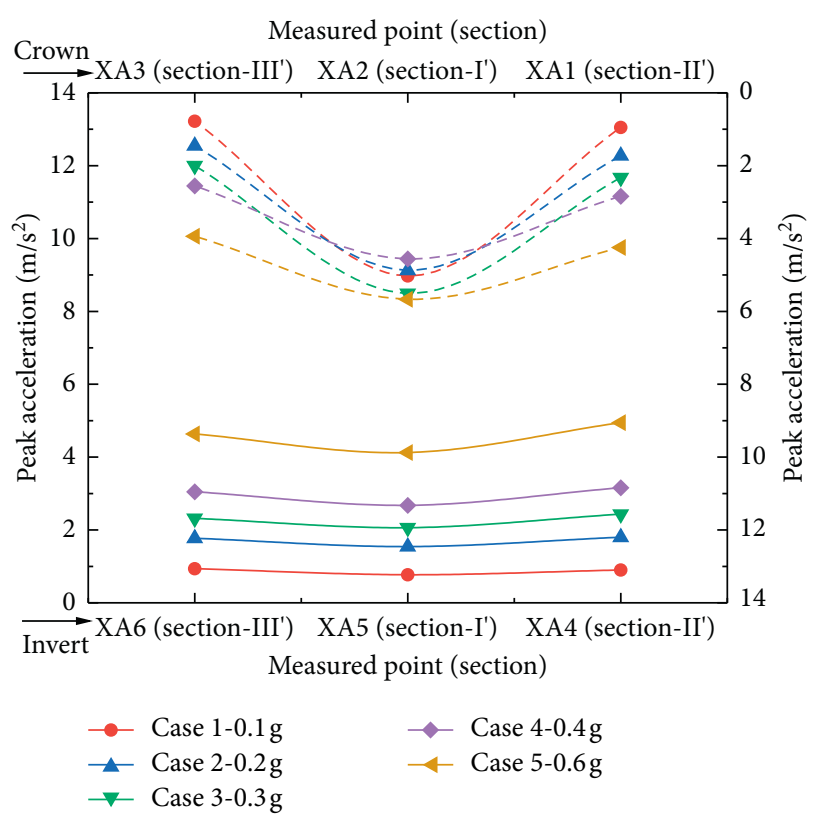

Figure 13: Peak acceleration of the upper-span tunnel.

We also use $R_{a}$ to denote the changing trend of crown and invert of the under-crossing tunnel, here. With the PGA of $0.1 \mathrm{~g}$, the peak acceleration of the crown (invert) of the section- $\mathrm{I}^{\prime}, \mathrm{II}^{\prime}$, and $\mathrm{III}^{\prime}$ is $3.94,0.94$, and $0.78 \mathrm{~m} / \mathrm{s}^{2}(0.77,0.93$, and $0.90 \mathrm{~m} / \mathrm{s}^{2}$ ), respectively. From Figure 15, it can be seen that owing to the existence of the upper-span tunnel, the peak acceleration at the cross section I' has little change, and the $R_{a}$ hovers around 1.0 under various cases. Further, the peak accelerations of the other measured points of each section are sensitive to the change of the seismic waves. The acceleration amplification effect has a small increase with the PGA of $0.2-0.4 \mathrm{~g}$, and the maximum $R_{a}$ is 2.70 , while the $R_{a}$ shows a sharp increase with the PGA of $0.4-0.6 \mathrm{~g}$, which reaches 5.50 .

3.2.2. Dynamic Strain. The circumferential strain of the central section (section- $\mathrm{I}^{\prime}$ ) of the under-crossing tunnel in different cases is summarized in Figure 16. Under low shaking intensity (Case 1 and Case 2), the peak strain of each measured point increases with the increase in the loading cases, and the "envelope" of the peak strain is basically the same as the upper-span tunnel, which is side walls (ZX8 and $Z X 7)>$ crown $(Z X 2)>$ invert $(Z X 5)$. When the inputted seismic wave amplitude is $0.3 \mathrm{~g}$, the peak strain "envelope" migrates to the right-side wall, and the maximum value of $27.53 \mu \varepsilon$ appears in the crown, which is $54.3 \%$ of the upperspan tunnel. When the inputted seismic wave amplitude is large ( $0.4 \mathrm{~g}$ and $0.6 \mathrm{~g}$ ), the "envelope" of peak strain gradually develops along the flat direction, indicating that when the seismic intensity is large, the response of the side wall is the strongest. However, the maximum strain on the side wall of the under-crossing tunnel is much smaller than that of the upper-span tunnel, which is only $11.1 \%$ of its peak strain.
The surrounding rock absorbs part of the seismic waves because of the large burial depth of the tunnel.

Figure 17 also presents $R_{s}$ of each case based on the PGA of $0.1 \mathrm{~g}$ (Case 1 ). The $R_{s}$ is approximately "teardrop-shaped," and the maximum $R_{s}$ generated by the crown is 1.42 , which indicates that the crown of the under-crossing tunnel is the most sensitive to the seismic load response, followed by the side walls, and the invert is the smallest. This rule also shows that with the increase in seismic intensity, there may be greater deformation at the crown of the under-crossing tunnel, while the invert is relatively stable.

Comparing the peak values of the circumferential strain of the upper-span tunnel and the under-crossing tunnel, it can be found that when the seismic intensity is small, the peak strains of the two crossing tunnels are basically the same. However, when the seismic intensity is high, the strain peak value of the upper-span tunnel is far greater than that of the under-crossing tunnel. The percentage of peak strain value of each measured point of the under-crossing tunnel to that of the upper-span tunnel is $11.1 \%$ for the side walls, $54 \%$ for the crown, and $62 \%$ for the invert. It is well known that owing to the interaction between the central sections of the tunnels, the existence of the upper-span tunnel weakens the dynamic response of the earthquake to the under-crossing tunnel. The same conclusion was reached in the studies of Sun et al. and Zhang et al. [45, 46].

3.3. Dynamic Response Analysis of the Interior Slope. To compare the similarities and differences of the acceleration response of the tunnel inside and outside the slope body, the location along the vertical centerline of the tunnel intersection, that is, the PA1-4 measured points inside the slope body are analyzed.

Form Figure 18, the acceleration amplification effect is not obvious with the PGA of $0.1-0.3 \mathrm{~g}$, while the acceleration amplification effect is more obvious along the elevation with the PGA of $0.4 \mathrm{~g}$ and $0.6 \mathrm{~g}$. Taking P4 measured point as an example under the cases of $0.4 \mathrm{~g}$ and $0.6 \mathrm{~g}$, it can be concluded that the acceleration amplification factors of P2 and P1 measured points are 1.05 and $1.22 ; 1.07$ and 1.32 , respectively; that is, the acceleration amplification factor is smaller at the bottom of the slope and larger at the top of the slope.

Generally, with the decrease in tunnel buried depth, the acceleration in surrounding rock and soil has amplification effect for a single tunnel, and the acceleration amplification coefficient gradually increases with the decrease in buried depth. However, the peak accelerations at all measured points inside the slope body (except for the measured point PA3 at the center of the intersection of the two tunnels) have an amplification effect along the elevation for the overlapped tunnel. Specifically, the peak acceleration of PA3 at the cross center is significantly greater than other parts of the slope under the same case. Owing to the reflection and refraction of the seismic wave between two tunnels, the superposition effect of acceleration will be produced in space. Therefore, 

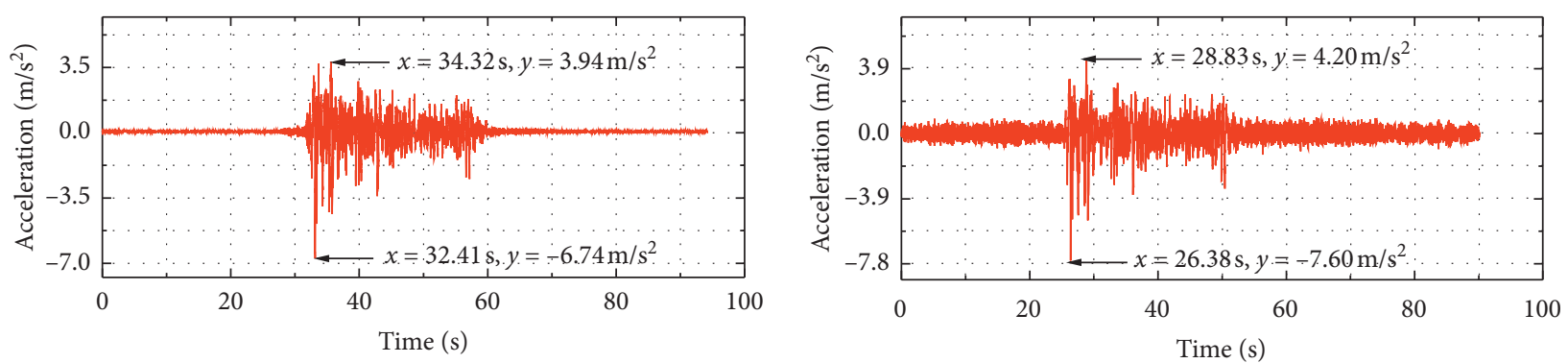

$-0.2 \mathrm{~g} \mathrm{EL}$

$-0.6 \mathrm{~g} \mathrm{EL}$
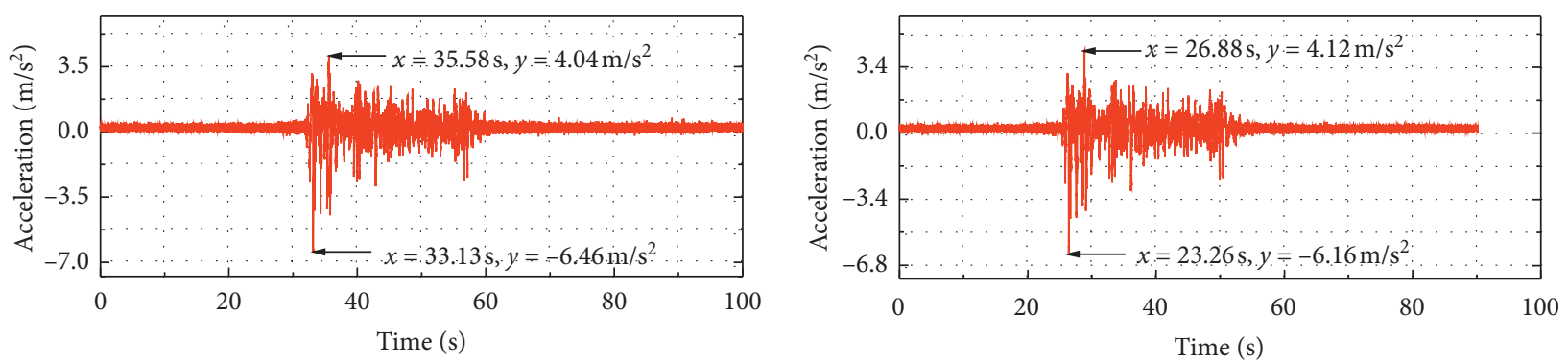

- $0.1 \mathrm{gEL}$

- $0.4 \mathrm{~g} \mathrm{EL}$
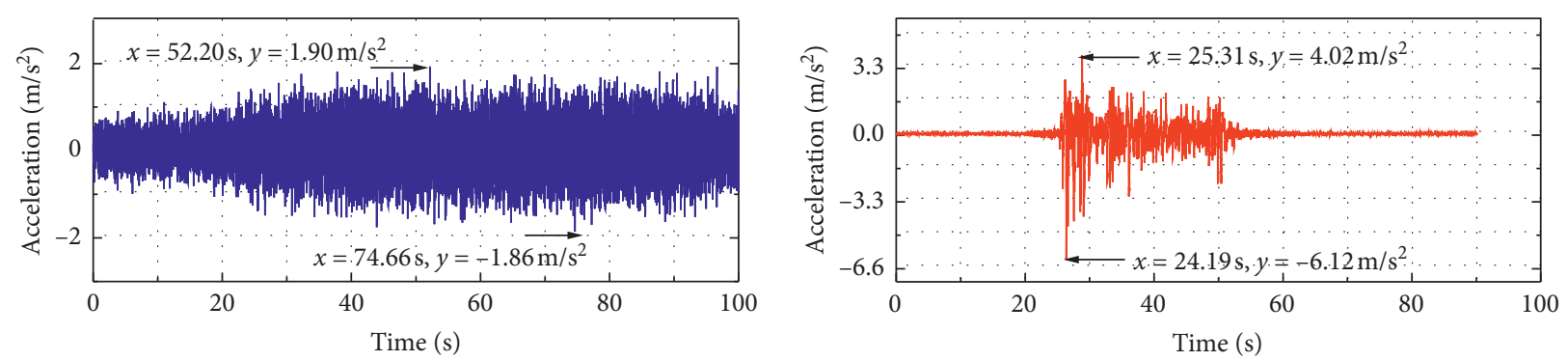

— $0.05 \mathrm{~g}$ sine-sweep

$-0.3 \mathrm{~g} \mathrm{EL}$

(a)

(b)

FIgURE 14: Time-history curve of acceleration at the crown (XA2) of the under-crossing tunnel.

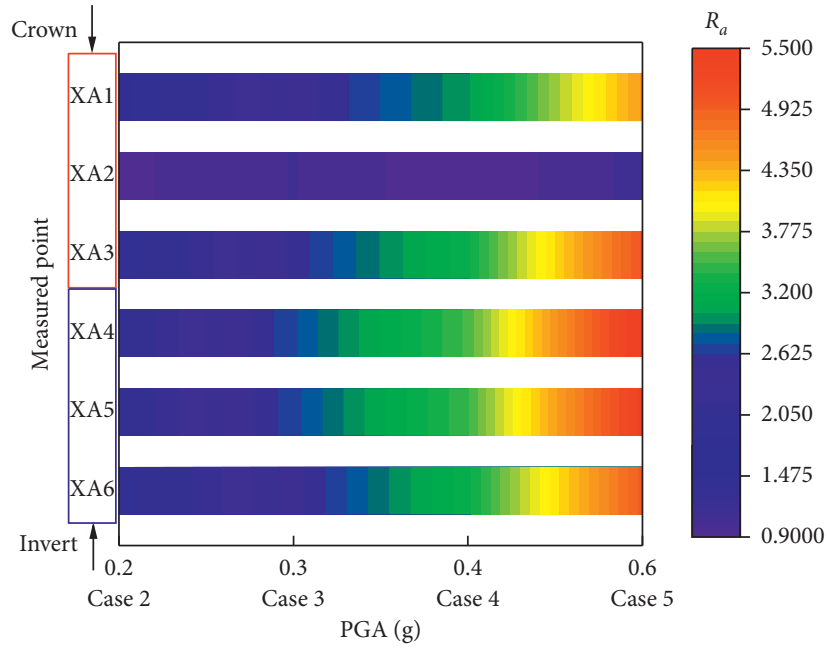

Figure 15: $R_{a}$ of the under-crossing tunnel. 


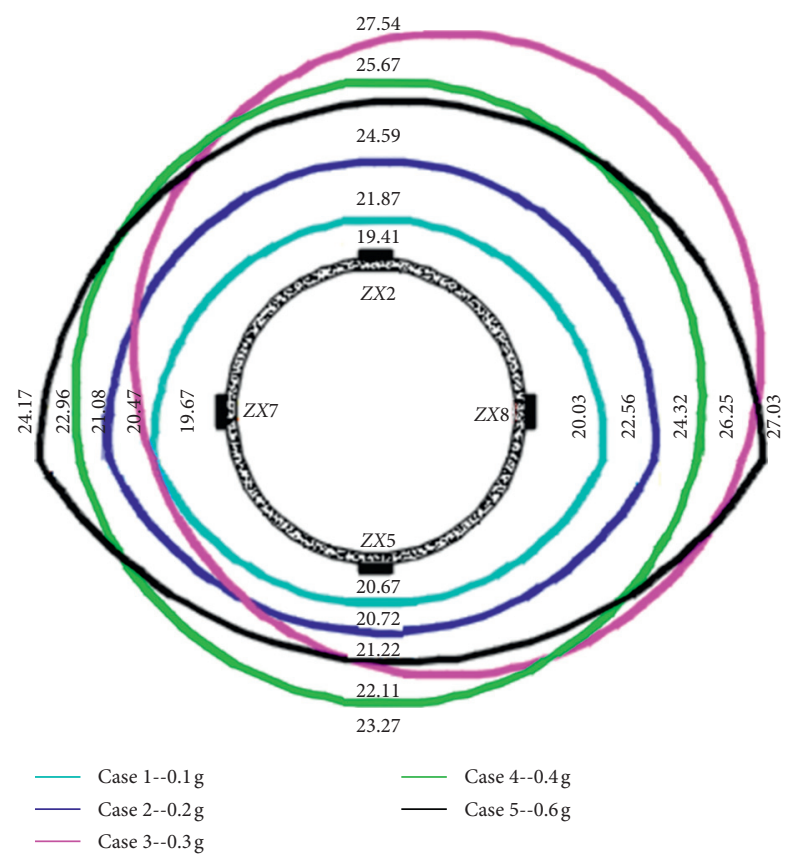

FIGURE 16: An envelope of circumferential peak strain of the undercrossing tunnel (unit: $\mu \varepsilon$ ).

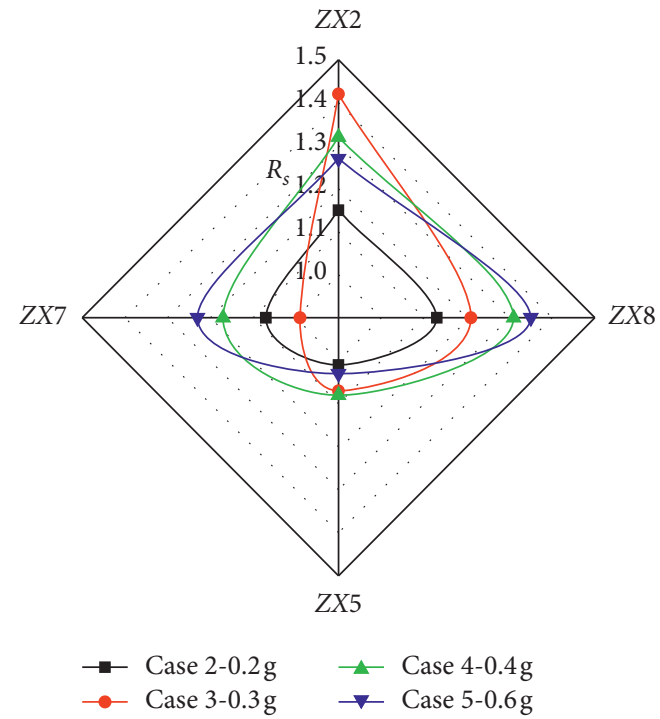

Figure 17: $R_{s}$ of the under-crossing tunnel.

the dynamic response of acceleration can provide necessary theoretical reference for seismic design of the overlapped tunnel.

\section{Dynamic Response Spectrum Analysis}

4.1. Energy Analysis Based on Wavelet Packet. Wavelet packet analysis can perform time-frequency localization and frequency band uniformization on signals with characteristics of short duration and nonstationary [47, 48]. In this section, the wavelet packet transform is used to decompose the acceleration signals of the invert (the upper-span tunnel)

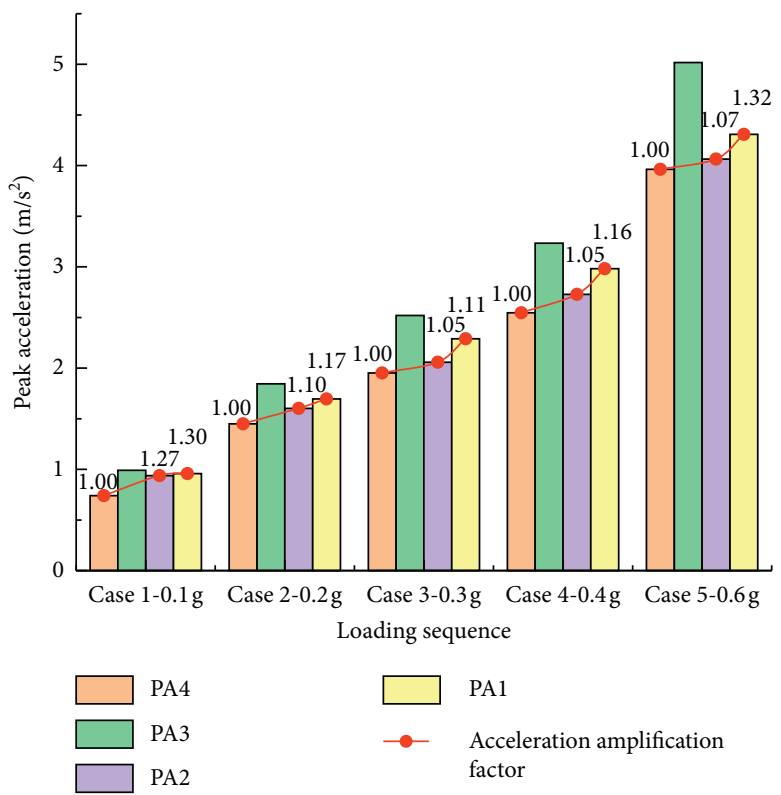

FIGURE 18: Peak acceleration and amplification factor in slope.

and the crown (the under-crossing tunnel), respectively. Furthermore, the eigenvalues of signal energy in each frequency band after decomposition are extracted so that the frequency band which has the main effect on different measured points in the invert and the crown of tunnels can be determined quantitatively.

4.1.1. Wavelet Packet Decomposition Layers and Basis Function. According to the principle of wavelet packet decomposition, the seismic waves can be decomposed at the infinite level when wavelet packet decomposition is adopted, but in the actual decomposition process, too low or too high decomposition layers are not conducive to the analysis of seismic waves [49]. When the number of decomposition layers is too low, the extraction effect of seismic wave information cannot reach the ideal level, while when the number of decomposition layers is too high, a false frequency phenomenon may occur and a higher resolution cannot be guaranteed. Moreover, with the increase in the number of decomposition layers, the number of computations increases, which results in the slow processing speed.

In general, we usually use the following formula to determine the number of decomposition layers of the wavelet packet [50]:

$$
0<k \leq \log _{2}\left(L_{S}\right) .
$$

Here, $k$ denotes the number of seismic wave decomposition layers and $L_{S}$ denotes the seismic wave signal number length.

In this shaking table test, the sampling time interval of the seismic wave signal is $0.02 \mathrm{~s}$, then the sampling frequency is $50 \mathrm{~Hz}$, and the duration of the ground motion signal is generally $10-20 \mathrm{~s}$, so the signal degree $L_{S}$ is about $2^{9}-2^{10}$. By substituting $L_{S}$ into equation (3), it can be concluded that the number of decomposition layers $k$ of wavelet packet is 
between 0 and 9. Considering the resolution and frequency bandwidth comprehensively, this paper believes that when the number of decomposition layers is 3 , it can meet the analysis requirements.

According to the Shannon sampling theorem [51], the Nyquist frequency is $0.1-50 \mathrm{~Hz}$. When 8-layer wavelet packet decomposition is performed on the collected signal, there are $2^{3}=8$ wavelet packets in total. Therefore, the width of each frequency band is $50 / 8=6.25 \mathrm{~Hz}$, and the corresponding minimum frequency band is $0.1-6.26 \mathrm{~Hz}$. Taking the eight frequency bands $(0.1-50 \mathrm{~Hz})$ as the object of analysis, the corresponding frequency range of each frequency band is shown in Table 4 .

Moreover, the wavelet functions used in wavelet analysis are various, and the effect of selecting different wavelet functions on signal processing will be different. The Daubechies (db wavelet) function in the wavelet function has good approximate symmetry, smoothness, and tight support, which has obvious advantages in the analysis of seismic and other unstable signals. The $\mathrm{db}$ wavelet function can be divided into $\mathrm{db} 1-\mathrm{db} 10$ wavelet bases according to the coefficient $\mathrm{N}$. In the current application, the most used are $\mathrm{db} 3$, $\mathrm{db} 5$, and $\mathrm{db} 8$. In this paper, $\mathrm{db} 3$ is selected as the wavelet basis function of this shaking table test.

\subsubsection{Acceleration Energy Analysis of the Invert (SA5) and the} Crown (XA2). The MATLAB program is used to extract the energy characteristic values of measured points SA5 and $\mathrm{XA} 2$ in the above frequency bands under the seismic wave action of Case 1-5. Further, the data in the program are used to make the acceleration energy ratio of each measured point of the tunnels in each frequency band, as shown in Figure 19.

Form Figure 19(a), it is implied that under the action of EL seismic waves in the cases, the acceleration energy characteristic value at the invert of the upper-span tunnel (SA5) reaches the maximum value in the 1 st dominant frequency $(0.1-6.26 \mathrm{~Hz})$. Additionally, the energy in the1st dominant frequency band at the invert accounts for more than $94 \%$ of the total energy, indicating that the main frequency band that affects the acceleration response at the invert is the 1st dominant frequency band. With the increase in inputted seismic wave amplitude, the proportion of energy in the 1st dominant frequency band frequency band increases, while the proportion of the 2 nd to 8 th dominant frequency bands $(6.26-50 \mathrm{~Hz})$ decreases.

The energy characteristic values at the crown of the under-crossing tunnel (XA2) in each frequency band have a very significant regularity. Figure 19(b) illustrates that the energy in the 1st dominant frequency band at XA2 accounts for more than $97 \%$ of the total energy, indicating that the main frequency band that affects the acceleration response at the crown is the 1 st dominant frequency $(0.1-6.26 \mathrm{~Hz})$.

By comparing the energy ratio, we found that under the same cases, the energy proportion of the invert of the undercrossing tunnel in the 1 st dominant frequency band is greater than that of the crown of the upper-span tunnel. Owing to the superposition effect of acceleration, the energy at the crown of the under-crossing tunnel increases, which is
TABLE 4: Frequency bands of wavelet packet decomposition.

\begin{tabular}{lc}
\hline Frequency band number & Frequency range $(\mathrm{Hz})$ \\
\hline $1^{\text {st }}$ & $0.1-6.26$ \\
$2^{\text {nd }}$ & $6.26-12.51$ \\
$3^{\text {rd }}$ & $12.51-18.76$ \\
$4^{\text {th }}$ & $18.76-25.01$ \\
$5^{\text {th }}$ & $25.01-31.26$ \\
$6^{\text {th }}$ & $31.26-37.51$ \\
$7^{\text {th }}$ & $37.51-43.76$ \\
$8^{\text {th }}$ & $43.76-50$ \\
\hline
\end{tabular}

also the part of the tunnel structure that is easy to be damaged in earthquake. It is shown that the low-frequency component plays a leading role in the tunnel failure process of the seismic load. Moreover, before the seismic wave propagates from the soil to the concrete, the low-frequency components will change dramatically due to the complex refraction and reflection relationship between the soil and the concrete interface.

4.2. Response Spectrum Variation Analysis. Generally, the monitoring data are usually the acceleration time-history curves of different measuring points after the shaking table model test. However, the spectrum characteristics of seismic waves cannot be accurately expressed from the original monitoring data. Therefore, it is necessary to introduce the seismic wave response spectrum to analyze the seismic wave characteristics which have an impact on the damage mode and development process of the tunnel and surrounding rock. The seismic response spectrum (including displacement spectrum, acceleration spectrum, and velocity spectrum) mainly reflects the impact of earthquake on the structure and can characterize the natural frequency (period) of the structure, which is widely used in the process of evaluating the dynamic response of the structure $[38,52]$.

The response spectrum is established on the basis of the vibration of the single particle system, which represents the characteristics of the influence of seismic waves on the structure represented by the single particle system. In the dynamic response spectrum analysis, the surrounding rock mass material at the location of the measuring point in the model can be regarded as a rigid body element. Thus, the dynamic response spectrum obtained can represent the curves of the maximum displacement response, velocity response, and acceleration response with the particle period in the given seismic wave excitation process of the rock and soil mass element at different positions of the tunnel, which has more engineering significance.

To study the variation law of the acceleration response spectrum of the cross tunnel in different surrounding rock positions, the acceleration measurement points of cross section with the peak acceleration of $0.15 \mathrm{~g}$ (low earthquake), $0.4 \mathrm{~g}$ (moderate earthquake), and $0.6 \mathrm{~g}$ (strong earthquake) seismic wave are selected as the research object for response spectrum analysis. The measuring points are crown and invert of the upper-span tunnel (SA2 and SA5), intersection center of slope (PA3), and crown and invert of the under- 


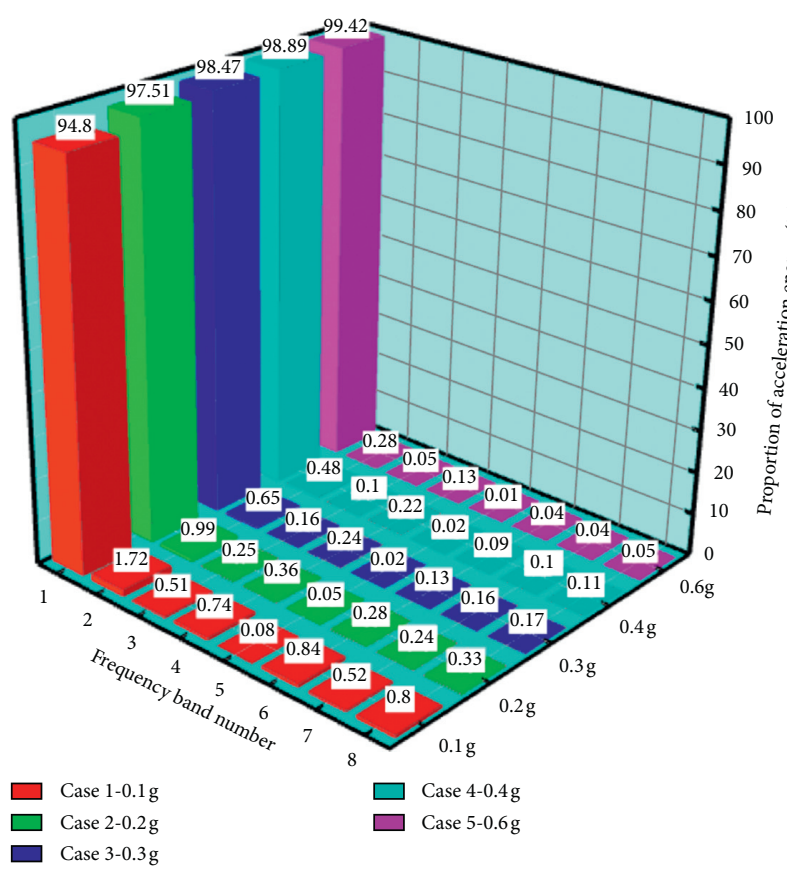

(a)

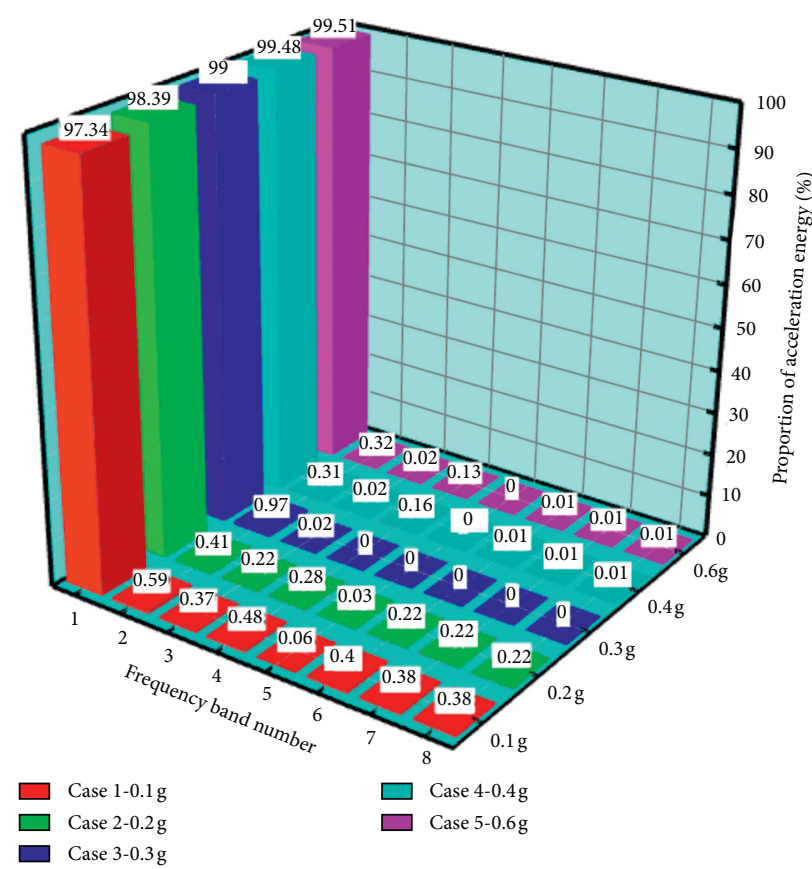

(b)

FIGURE 19: Proportion of acceleration energy of (a) the invert (SA5) and (b) the crown (XA2).
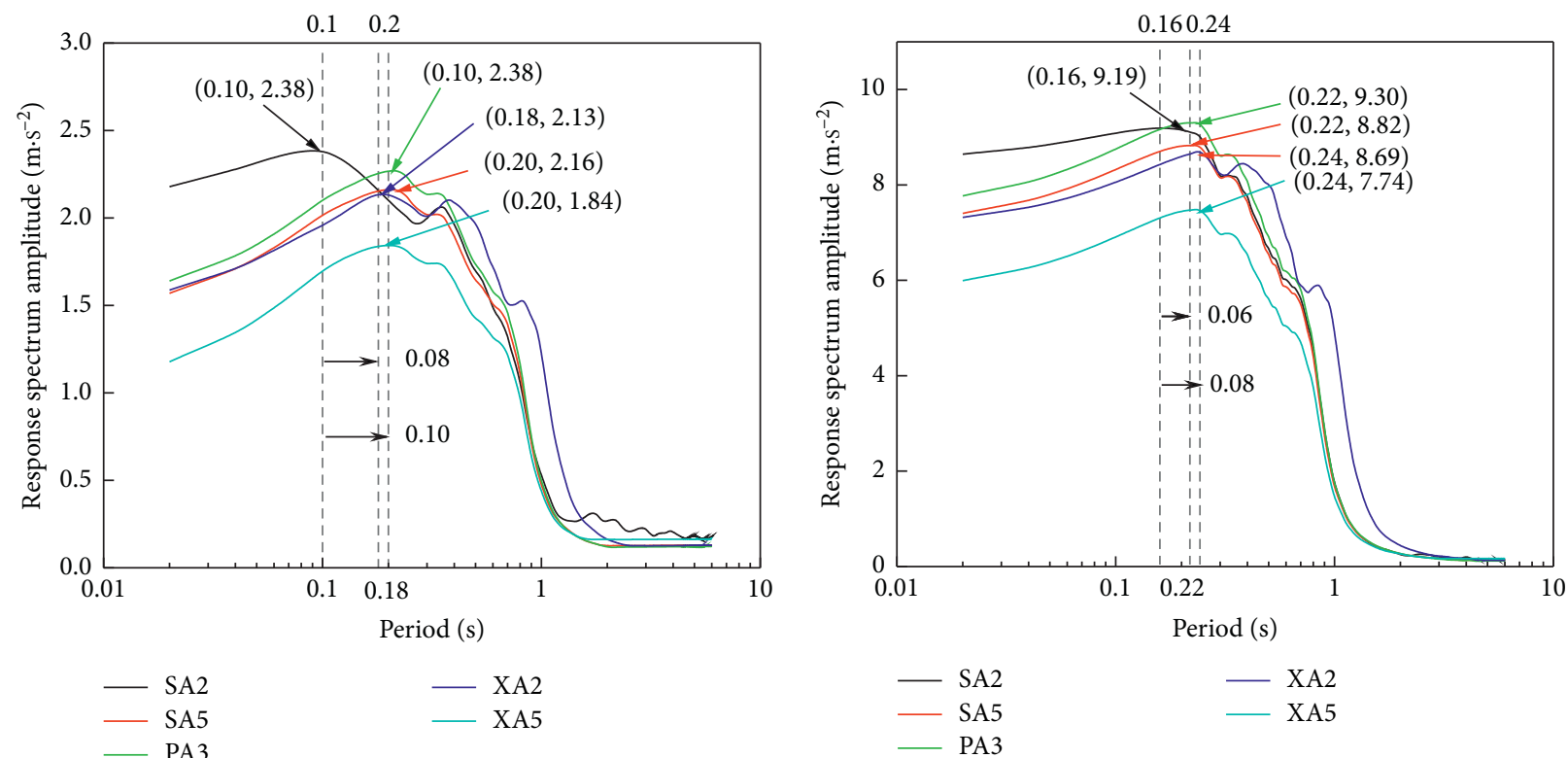

(a)

(b)

FIgure 20: Continued. 


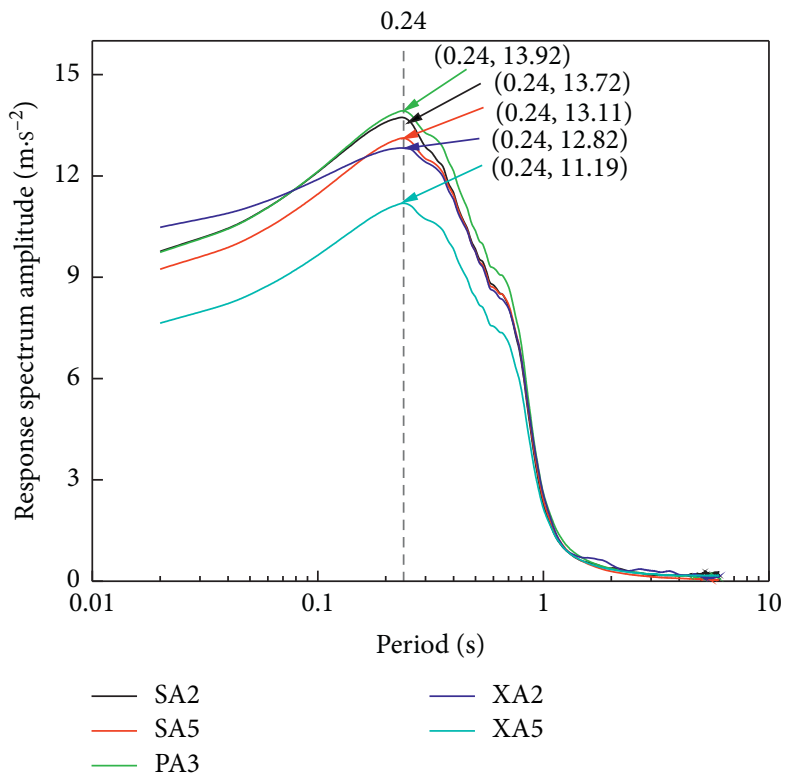

(c)

FIGURE 20: Response spectrum of acceleration at different positions under EL-Centro wave loading: (a) $0.1 \mathrm{~g}$; (b) $0.4 \mathrm{~g}$; (c) $0.6 \mathrm{~g}$.

crossing tunnel (XA2 and XA5), and the vertical distances from the measuring points to the bottom of the slope are $0.63 \mathrm{~m}, 0.43 \mathrm{~m}, 0.39 \mathrm{~m}, 0.35 \mathrm{~m}$, and $0.15 \mathrm{~m}$, respectively. It should be noted that the acceleration response spectrum calculation process used a $5 \%$ damping ratio commonly used in engineering to carry out, and the response spectrum curve was smoothed by the Origin software so as to express the predominant period of the acceleration response spectrum more clearly.

The response spectrum of acceleration at different positions under different amplitude EL-Centro wave loading is shown in Figure 20.

It can be obtained that the shape of the acceleration response spectrum of each measuring point is basically the same, with obvious peak characteristics. In the short period part $(T=0.02 \sim 0.30 \mathrm{~s})$, the response spectrum distribution curve of each measuring point has obvious amplification effect along the elevation (except for PA3 intersection center of slope). The reason for this phenomenon is analyzed owing to the refraction and reflection of seismic waves between tunnels, which will produce a superposition effect of the response spectrum in space, resulting in the abnormal increase in acceleration spectrum amplitude of PA3. However, in the remaining long period part (low-frequency part), the amplification effect of the response spectrum along the elevation is not obvious. With the increase in the predominant period, the amplitude of the response spectrum decreases. When the predominant period is $2 \mathrm{~s}$, the amplitude of the acceleration response spectrum is basically 0 .

Moreover, Figure 20(a) presents the predominant period corresponding to the peak value of the response spectrum of SA2 is concentrated at $T=0.10 \mathrm{~s}$, which is earlier than other measurement points, and its corresponding predominant frequency is $10 \mathrm{~Hz}$. The reason is that under the action of $0.1 \mathrm{~g}$ seismic waves, slight damage may occur at the crown of the upper-span tunnel, which leads to a large difference in response spectrum amplitude between SA2 and other measuring points. It is seen that the SA2 also showed the phenomenon of forward migration of the predominant period when $0.4 \mathrm{~g}$ seismic wave loading in Figure 20(b), which shows that under the loading of low and moderate earthquakes, the crown of the upper-span tunnel will be the earliest and prone to damage. At the same time, the maximum amplitude acceleration response spectrum of PA3 when $0.2 \mathrm{~g}$ loaded is $9.30 \mathrm{~m} / \mathrm{s}^{2}$, which is 4.11 times larger than the $2.26 \mathrm{~m} / \mathrm{s}^{2}$ when $0.1 \mathrm{~g}$ loaded. With the increase in the peak value of the input wave, the predominant period of the acceleration response spectrum of each measuring point has increased; that is, the predominant frequency has decreased, indicating that the nonlinear characteristics of the slope have become more obvious. Taking PA3 as an example, the input seismic wave increases from $0.1 \mathrm{~g}$ to $0.4 \mathrm{~g}$ to $0.6 \mathrm{~g}$, and its predominant period (predominant frequency) is $0.20 \mathrm{~s}, 0.22 \mathrm{~s}$, and $0.24 \mathrm{~s}(5 \mathrm{~Hz}, 4.54 \mathrm{~Hz}$, and $4.17 \mathrm{~Hz})$, respectively. Furthermore, the surrounding rock mass has an amplification effect on low-frequency seismic waves.

\section{Conclusion}

In order to examine the distribution and variation of the acceleration and dynamic strain of the oblique overlapped tunnel during earthquakes, a series of shaking table model tests were carried out, which were the inputted EL-Centro wave in the horizontal with the PGA of $0.1-0.6 \mathrm{~g}$. Based on the recorded data, as well as observations on the post-test behaviors of the model, we analyzed features of the acceleration and dynamic strain of the upper-span and the 
under-crossing tunnels, as well as the main factors resulting in the changes. At the same time, the wavelet packet was used to study the acceleration energy ratio of the invert (the upper-span tunnel) and the crown (the under-crossing tunnel). Some conclusions are summarized as follows:

(1) The peak acceleration of the crown of the upper-span and the under-crossing tunnels is the largest at the central section ( $\mathrm{I}$ and $\mathrm{I}^{\prime}$ ) which is the key part of the tunnel structure that be paid attention to in the antiseismic process, and the seismic response of sections on both sides of the affected section is basically the same. However, the peak acceleration of the invert of the tunnels is exactly opposite to the crown, which presents a "parabolic" distribution. This kind of variation of acceleration dynamic response provides evidence for the practical design of the overlapped tunnel during the earthquake.

(2) When the tunnels were subjected to shaking with low seismic intensities (with the PGA of $0.1 \mathrm{~g}$ and $0.2 \mathrm{~g}$ ), the hoop peak strains of the two tunnels are basically stable, and the failure modes of the two tunnels are in the form of transmission evolution from crown to side walls to invert. Additionally, the strain in the upper-span tunnel is much larger than that in the under-crossing tunnel under the moderate and high shaking intensity (with the PGA of $0.3 \mathrm{~g}-0.6 \mathrm{~g}$ ), whose the peak strains of the upper-span tunnel are side walls $>$ crown $>$ invert and crown $>$ side wall$\mathrm{s}>$ invert for the under-crossing tunnel.

(3) Different from the single tunnel, because of the spatial effect of overlapping tunnel, the acceleration superposition effect appears in the intersection section of two tunnels, which leads to the obvious seismic response in the cross section. The peak acceleration inside the slope body has an amplification effect along the elevation except for cross section. Further, the acceleration amplification factor gradually decreases with the increase in the buried depth of the measured points.

(4) The low-frequency component $(0.1-6.26 \mathrm{~Hz})$ seismic wave plays a leading role in the process of tunnel slope failure, and owing to the superposition effect of acceleration, the energy proportion of the invert of the under-crossing tunnel in the 1st dominant frequency band is greater than that of the crown of the upper-span tunnel. With the increase in the peak value of the input wave, the predominant frequency has decreased, indicating that the nonlinear characteristics of the slope have become more obvious. Furthermore, the surrounding rock mass has an amplification effect on low-frequency seismic waves.

\section{Data Availability}

The data used to support the findings of this study are available from the corresponding author upon request.

\section{Conflicts of Interest}

The authors declare that they have no conflicts of interest.

\section{Authors' Contributions}

Hoa Lei and Honggang $\mathrm{Wu}$ contributed equally to this work and are co-first authors.

\section{Acknowledgments}

The research was supported by the National Key R\&D Program of China (2018YFC1504903) and the Science and Technology Development Project of China Railway Nine Bureau Group Co., Ltd. Dalian Branch (KJ-2019-01). The authors gratefully acknowledge the support from the Key Laboratory of Loess Earthquake Engineering, CEA.

\section{References}

[1] K. Konagai, S. Takatsu, T. Kanai, T. Fujita, T. Ikeda, and J. Johansson, "Kizawa tunnel cracked on 23 October 2004 Mid-Niigata earthquake: an example of earthquake-induced damage to tunnels in active-folding zones," Soil Dynamics and Earthquake Engineering, vol. 29, no. 2, pp. 394-403, 2009.

[2] G. C. Wang, J. Yao, L. Sha, L. C. Yu, and X. W. Zheng, "Analysis on the seismic response of hangzhou metro tunnel in soft soils," Advanced Materials Research, vol. 446-449, pp. 966-969, 2012.

[3] J. T. Chen, Y. Yuan, and H. T. Yu, "Dynamic response of segmental lining tunnel," Geotechnical Testing Journal, vol. 43, no. 3, pp. 660-682, 2019.

[4] JR. Standing and R. Selman, The Response to Tunnelling of Existing Tunnels at Waterloo and Westminster. Building Response to Tunnelling: Case Studies from Construction of the Jubilee Line Extension, Thomas Telford Publishing, London, UK, 2001.

[5] H. Mohamad, P. J. Bennett, K. Soga, R. J. Mair, and K. Bowers, "Behaviour of an old masonry tunnel due to tunnelling-induced ground settlement," Géotechnique, vol. 60, no. 12, pp. 927-938, 2010.

[6] Q. Fang, D. Zhang, Q. Li, and L. N. Y. Wong, "Effects of twin tunnels construction beneath existing shield-driven twin tunnels," Tunnelling and Underground Space Technology, vol. 45, pp. 128-137, 2015.

[7] G. Gazetas, N. Gerolymos, and I. Anastasopoulos, "Response of three Athens metro underground structures in the 1999 Parnitha earthquake," Soil Dynamics and Earthquake Engineering, vol. 25, no. 7-10, pp. 617-633, 2005.

[8] G. J. Parra-Montesinos, A. Bobet, and J. A. Ramirez, "Evaluation of soil-structure interaction and structural collapse in Daikai subway station during Kobe earthquake," ACI Structural Journal, vol. 103, no. 1, pp. 113-122, 2006.

[9] I. Anastasopoulos, N. Gerolymos, V. Drosos, R. Kourkoulis, T. Georgarakos, and G. Gazetas, "Nonlinear response of deep immersed tunnel to strong seismic shaking," Journal of Geotechnical and Geoenvironmental Engineering, vol. 133, no. 9, pp. 1067-1090, 2007.

[10] G. Andreotti and C. G. Lai, "Use of fragility curves to assess the seismic vulnerability in the risk analysis of mountain tunnels," Tunnelling and Underground Space Technology, vol. 91, Article ID 103008, 2019. 
[11] Y. M. A. Hashash, J. J. Hook, B. Schmidt, and J. I-Chiang Yao, "Seismic design and analysis of underground structures," Tunnelling and Underground Space Technology, vol. 16, no. 4, pp. 247-293, 2001.

[12] U. Cilingir and S. P. Gopal Madabhushi, "A model study on the effects of input motion on the seismic behaviour of tunnels," Soil Dynamics and Earthquake Engineering, vol. 31, no. 3, pp. 452-462, 2011.

[13] J.-H. Hwang and C.-C. Lu, "Seismic capacity assessment of old Sanyi railway tunnels," Tunnelling and Underground Space Technology, vol. 22, no. 4, pp. 433-449, 2007.

[14] S. Kontoe, V. Avgerinos, and D. M. Potts, "Numerical validation of analytical solutions and their use for equivalentlinear seismic analysis of circular tunnels," Soil Dynamics and Earthquake Engineering, vol. 66, pp. 206-219, 2014.

[15] JX. Lai, KY. Wang, JL. Qiu et al., "Vibration response characteristics of the cross tunnel structure," Shock and Vibration, vol. 2016, Article ID 9524206, 16 pages, 2016.

[16] F. Khoshnoudian and I. Shahrour, "Numerical analysis of the seismic behavior of tunnels constructed in liquefiable soils," Soils and Foundations, vol. 42, no. 6, pp. 1-8, 2002.

[17] J.-H. Ding, X.-L. Jin, Y.-Z. Guo, and G.-G. Li, "Numerical simulation for large-scale seismic response analysis of immersed tunnel," Engineering Structures, vol. 28, no. 10, pp. 1367-1377, 2006.

[18] Q. Sun and D. Dias, "Significance of Rayleigh damping in nonlinear numerical seismic analysis of tunnels," Soil Dynamics and Earthquake Engineering, vol. 115, pp. 489-494, 2018.

[19] Q. Q. Sun and D. Dias, “Assessment of stress relief during excavation on the seismic tunnel response by the pseudostatic method," Soil Dynamics and Earthquake Engineering, vol. 117, pp. 384-397, 2019.

[20] H. Xu, T. Li, L. Xia, J. X. Zhao, and D. Wang, "Shaking table tests on seismic measures of a model mountain tunnel," Tunnelling and Underground Space Technology, vol. 60, pp. 197-209, 2016.

[21] G. Tsinidis, "Response characteristics of rectangular tunnels in soft soil subjected to transversal ground shaking," Tunnelling and Underground Space Technology, vol. 62, pp. 1-22, 2017.

[22] U. Cilingir and S. P. G. Madabhushi, "Effect of depth on the seismic response of square tunnels," Soils and Foundations, vol. 51, no. 3, pp. 449-457, 2011.

[23] Z. Y. Chen and H. Shen, "Dynamic centrifuge tests on isolation mechanism of tunnels subjected to seismic shaking," Tunnelling and Underground Space Technology, vol. 42, pp. 67-77, 2014.

[24] H. Yu, X. Yan, A. Bobet, Y. Yuan, G. Xu, and Q. Su, "Multipoint shaking table test of a long tunnel subjected to nonuniform seismic loadings," Bulletin of Earthquake Engineering, vol. 16, no. 2, pp. 1041-1059, 2018.

[25] Y. Yong, H. Yu, C. Li et al., "Multi-point shaking table test for long tunnels subjected to non-uniform seismic loadings-Part I: theory and validation," Soil Dynamics and Earthquake Engineering, vol. 108, pp. 177-186, 2018.

[26] H. Yu, Y. Yuan, G. Xu, Q. Su, X. Yan, and C. Li, "Multi-point shaking table test for long tunnels subjected to non-uniform seismic loadings - part II: application to the HZM immersed tunnel," Soil Dynamics and Earthquake Engineering, vol. 108, pp. 187-195, 2018.

[27] R. E. S. Moss and V. A. Crosariol, "Scale model shake table testing of an underground tunnel cross section in soft clay," Earthquake Spectra, vol. 29, no. 4, pp. 1413-1440, 2013.
[28] G. Chen, Z. Wang, X. Zuo, X. Du, and H. Gao, "Shaking table test on the seismic failure characteristics of a subway station structure on liquefiable ground," Earthquake Engineering \& Structural Dynamics, vol. 42, no. 10, pp. 1489-1507, 2013.

[29] Z. Chen, W. Chen, Y. Li, and Y. Yuan, "Shaking table test of a multi-story subway station under pulse-like ground motions," Soil Dynamics and Earthquake Engineering, vol. 82, pp. 111122, 2016.

[30] B. L. Kutter, J. C. Chou, and T. Travasarou, "Centrifuge testing of the seismic performance of a submerged cut-and-cover tunnel in liquefiable soil," in Proceedings of the Geotechnical Earthquake Engineering and Soil Dynamics IV, Sacramento, CA, USA, May, pp. 1-29, 2008.

[31] G. Tsinidis, K. Pitilakis, G. Madabhushi, and C. Heron, "Dynamic response of flexible square tunnels: centrifuge testing and validation of existing design methodologies," Géotechnique, vol. 65, no. 5, pp. 401-417, 2015.

[32] D. Zhao, J. Shen, G. Chen, and J. Zhu, "Shaking table experimental study on time-frequency characteristics of subway stations constructed in different materials," in Proceedings of the GSIC 2018: Proceedings of GeoShanghai 2018 International Conference: Advances in Soil Dynamics and Foundation Engineering, Singapore, 2018.

[33] Z. Wu, D. Zhang, S. Wang, C. Liang, and D. Zhao, "Dynamicresponse characteristics and deformation evolution of loess slopes under seismic loads," Engineering Geology, vol. 267, Article ID 105507, 2020.

[34] J. Zhang, Y. Yuan, Z. Bao, H. Yu, and E. Bilotta, "Shaking table tests on the intersection of cross passage and twin tunnels," Soil Dynamics and Earthquake Engineering, vol. 124, pp. 136-150, 2019.

[35] C. L. Xin, Z. Z. Wang, J. M. Zhou, and B. Gao, "Shaking table tests on seismic behavior of polypropylene fiber reinforced concrete tunnel lining," Tunnelling and Underground Space Technology, vol. 88, pp. 1-15, 2019.

[36] X. N. Deng, Y. H. Jiang, Z. J. Wang, F. C. Liu, and J. J. Zhang, "Similitude material confecting of tunnel model in shaking table test," Applied Mechanics and Materials, vol. 501-504, pp. 1774-1778, 2014.

[37] Y. Miao, W. Wei, and R. Chen, "Orthogonal experiment on the mixture ratio of soil similar material," Journal of Fuzhou University, vol. 44, no. 4, pp. 570-576, 2016, in Chinese.

[38] N. Ma, H. Wu, H. Ma, X. Wu, and G. Wang, "Examining dynamic soil pressures and the effectiveness of different pile structures inside reinforced slopes using shaking table tests," Soil Dynamics and Earthquake Engineering, vol. 116, pp. 293-303, 2019.

[39] W. Wu, S. Ge, Y. Yuan, W. Ding, and I. Anastasopoulos, "Seismic response of subway station in soft soil: shaking table testing versus numerical analysis," Tunnelling and Underground Space Technology, vol. 100, Article ID 103389, 2020.

[40] C. Liu, L.-m. Peng, M.-f. Lei, and Y.-f. Li, "Research on crossing tunnels' seismic response characteristics," KSCE Journal of Civil Engineering, vol. 23, no. 11, pp. 4910-4920, 2019.

[41] N. Li, Y. M. Men, Y. Gao et al., "Research on seismic dynamic response of landslide supported by micro-pile group," Chinese Journal of Rock Mechanics and Engineering, vol. 37, no. 09, pp. 2144-2151, 2018, in Chinese.

[42] H. G. Wu, Z. X. Wu, X. L. Xie et al., "Large-scale shaking table test on micro-pile composite structure on soil slope," Rock and Soil Mechanics, vol. 40, no. 10, pp. 3844-3854, 2019, in Chinese. 
[43] G. Wang, M. Yuan, Y. Miao, J. Wu, and Y. Wang, "Experimental study on seismic response of underground tunnel-soilsurface structure interaction system," Tunnelling and Underground Space Technology, vol. 76, pp. 145-159, 2018.

[44] G. Tsinidis, "Response of urban single and twin circular tunnels subjected to transversal ground seismic shaking," Tunnelling and Underground Space Technology, vol. 76, pp. 177-193, 2018.

[45] T. Sun, Z. Yue, B. Gao, Q. Li, and Y. Zhang, "Model test study on the dynamic response of the portal section of two parallel tunnels in a seismically active area," Tunnelling and Underground Space Technology, vol. 26, no. 2, pp. 391-397, 2011.

[46] W. Zhang, X. Jin, and Z. Yang, "Combined equivalent \& multi-scale simulation method for 3-D seismic analysis of large-scale shield tunnel," Engineering Computations, vol. 31, no. 3, pp. 584-620, 2014.

[47] D. Huang, S. Cui, and X. Li, "Wavelet packet analysis of blasting vibration signal of mountain tunnel," Soil Dynamics and Earthquake Engineering, vol. 117, pp. 72-80, 2019.

[48] Y. Pan, L. Zhang, X. Wu, K. Zhang, and M. J. Skibniewski, "Structural health monitoring and assessment using wavelet packet energy spectrum," Safety Science, vol. 120, pp. 652-665, 2019.

[49] D. F. Zhang, MATLAB Wavelet Analysis, China Machine Press, Beijing, China, 2012, in Chinese.

[50] T. H. Ling, X. B. Li, T. G. Dai, and Z. B. Peng, "Features of energy distribution for blast vibration signals based on wavelet packet decomposition," Journal of Central South University of Technology, vol. 12, no. 1, pp. 135-140, 2005.

[51] H. Bray, K. McCormick, R. O Wells Jr., and X. D. Zhou, "Wavelet variations on the Shannon sampling theorem," Bio Systems, vol. 34, no. 1-3, pp. 249-257, 1995.

[52] I. G. Papandreou and G. A. Papagiannopoulos, "On the jerk spectra of some inelastic systems subjected to seismic motions," Soil Dynamics and Earthquake Engineering, vol. 126, Article ID 105807, 2019. 